\title{
The Sinorhizobium fredii HH103 MucR1 Global Regulator Is Connected With the nod Regulon and Is Required for Efficient Symbiosis With Lotus burttii and Glycine max cv. Williams
}

\author{
Sebastián Acosta-Jurado, ${ }^{1}$ Cynthia Alias-Villegas, ${ }^{1}$ Pilar Navarro-Gómez, ${ }^{1}$ Susanne Zehner, ${ }^{2}$ \\ Piedad del Socorro Murdoch, ${ }^{3}$ Miguel A. Rodríguez-Carvajal , ${ }^{4}$ María J. Soto, ${ }^{5}$ Francisco-Javier Ollero, ${ }^{1}$ \\ José E. Ruiz-Sainz, ${ }^{1}$ Michael Göttfert, ${ }^{2}$ and José-María Vinardell ${ }^{1}$ \\ ${ }^{1}$ Departamento de Microbiología, Facultad de Biología, Universidad de Sevilla, Avda. Reina Mercedes 6, C.P. 41012, Sevilla, \\ Spain, ${ }^{2}$ Technische Universität Dresden, Institut für Genetik, Helmholtzstrasse 10, 01062 Dresden, Germany, ${ }^{3}$ Departamento \\ de Bioquímica Vegetal y Biología Molecular, Facultad de Biología, Universidad de Sevilla, ${ }^{4}$ Departamento de Química Orgánica, \\ Facultad de Química, Universidad de Sevilla, Calle Profesor García González 1, C. P. 41012, Sevilla, Spain, and ${ }^{5}$ Departamento \\ de Microbiología del Suelo y Sistemas Simbióticos, Estación Experimental del Zaidín, CSIC, 18008 Granada, Spain
}

Accepted 27 July 2016.

\begin{abstract}
Sinorhizobium fredii HH103 is a rhizobial strain showing a broad host range of nodulation. In addition to the induction of bacterial nodulation genes, transition from a free-living to a symbiotic state requires complex genetic expression changes with the participation of global regulators. We have analyzed the role of the zinc-finger transcriptional regulator MucR1 from $S$. fredii $\mathrm{HH} 103$ under both free-living conditions and symbiosis with two HH103 host plants, Glycine max and Lotus burttii. Inactivation of HH103 mucRI led to a severe decrease in exopolysaccharide (EPS) biosynthesis but enhanced production of external cyclic glucans (CG). This mutant also showed increased cell aggregation capacity as well as a drastic reduction in nitrogen-fixation capacity with $G$. $\max$ and $L$. burttii. However, in these two legumes, the number of nodules induced by the mucRl mutant was significantly increased and decreased, respectively, with respect to the wild-type strain, indicating that MucR1 can differently affect nodulation depending on the host plant. RNA-Seq analysis carried out in the absence and the presence of flavonoids showed that MucR1 controls the expression of hundreds of genes (including some related to EPS production and CG transport), some of them being related to the nod regulon.
\end{abstract}

Legumes and a group of soil proteobacteria collectively called rhizobia (Peix et al. 2015) are able to establish a symbiotic interaction in which the microsymbiont infects plant

RNA-Seq data have been deposited in the Sequence Read Archive of the National Center for Biotechnology Information (BioProject database) under the BioProjects ID PRJNA313151 and PRJNA324263.

Current address for S. Zehner: Abteilung Mikrobiologie, Fachbereich Biologie, Technische Universität Kaiserslautern, Erwin Schrödinger Straße 56, 67663 Kaiserslautern, Germany.

Corresponding author: J. M. Vinardell; Telephone: +1 34-954554330; Fax: +1 34-954557830; E-mail: jvinar@us.es

*The $\boldsymbol{e}$-Xtra logo stands for "electronic extra" and indicates that eight supplementary figures, one supplementary table, six supplementary datasets, and supplementary methods are published online.

() 2016 The American Phytopathological Society roots and multiplies inside a new plant organ, the nodule, in which they differentiate into nitrogen-fixing bacteroids (Oldroyd 2013; Suzaki and Kawaguchi 2014). This symbiosis is driven by a complex interchange of molecular signals between both symbionts, and therefore, the participation of diverse regulatory elements is required for a successful interaction (Downie 2010; Janczarek et al. 2015; López-Baena et al. 2016). On the bacterial side, the LysR-type transcriptional regulator NodD is activated by flavonoids exuded by the plant and induces the expression of bacterial genes related to the production of nodulation factors. These molecular signals are perceived by the plant, allowing root infection and triggering the nodule developmental program. In some rhizobia, NodD and plant flavonoids also induce the formation of a symbiotic type III secretion system (T3SS) able to inject effector proteins into plant cells in order to reduce plant defense responses (López-Baena et al. 2016). Diverse bacterial surface polysaccharides also participate in the symbiosis, acting as molecular signals required for one or both infection progression or diminishing defense responses. In addition to NodD (which can be present in different copies having different roles), other transcriptional regulators, such as TtsI (responsible for expression of the symbiotic T3SS), SyrM, and NolR, are necessary for the transition from a free-living to a symbiotically competent state and, therefore, for a successful interaction. In fact, NolR is a global regulatory protein, which, in S. meliloti, is required not only for the optimization of nodulation but also for bacterial growth and survival and conjugative transfer of a plasmid (Chen et al. 2005).

The RosR/MucR protein family is composed of transcriptional regulators that contain a $\mathrm{Cys}_{2} \mathrm{His}_{2}$ type zinc-finger motif (Keller et al. 1995). They are widely distributed in proteobacteria, in which they regulate very diverse processes, such as cell-cycle transition from S-phase to G1 in Caulobacter (Fumeaux et al. 2014), alginate production in the opportunistic pathogen Pseudomonas aeruginosa (Wang et al. 2015), or expression of the plant oncogene ipt in Agrobacterium spp. (Chou et al. 1998). In the animal pathogen Brucella melitensis, genes encoding a type IV secretion or a quorum-sensing system are downregulated in a $m u c R$ deletion mutant (Dong et al. 2013). In Rhizobium leguminosarum bv. trifolii and Sinorhizobium meliloti, RosR/MucR were first described as positive regulators of exopolysaccharide (EPS) biosynthesis (Janczarek and Skorupska 2007; Keller et al. 
1995). In addition, in the case of $R$. leguminosarum bv. trifolii, inactivation of rosR led to ineffective symbiosis with Trifolium spp. More recent works showed that the RosR protein of $R$. leguminosarum bv. trifolii regulates different processes, such as the synthesis of cell-surface components (including polysaccharides), motility, and bacterial metabolism (Janczarek et al. 2010; Rachwał et al. 2015). Therefore, RosR plays an important role in bacterial adaptation to environmental conditions. During the preparation of this manuscript, Jiao et al. (2016) reported that Sinorhizobium fredii CCBAU45436 MucR1 is essential for supporting nitrogen fixation of this strain in Glycine max JD17 nodules. In that work, the authors also provided a transcriptomic analysis showing that MucR1 positively regulates the expression of different inorganic ion transporters required for effective nitrogen fixation in CCBAU45436 bacteroids.

In this work, we have studied the regulatory roles of MucR1 in $S$. fredii $\mathrm{HH103,} \mathrm{a} \mathrm{broad} \mathrm{host} \mathrm{range} \mathrm{rhizobial} \mathrm{strain} \mathrm{able} \mathrm{to}$ nodulate American and Asiatic varieties of soybean (López-Baena et al. 2016; Margaret et al. 2011; Vinardell et al. 2015). Inactivation of HH103 mucRl decreased EPS and increased external cyclic glucans $(\mathrm{CG})$ production, enhanced biofilm formation at the liquidair interface (pellicle) and autoaggregation, and led to a severe impairment in symbiosis with Lotus burttii and Glycine max cv. Williams. Although, in both cases, host plants inoculated with the mucRl mutant showed symptoms of nitrogen starvation, the number of nodules formed were significantly decreased with Lotus burttii and increased with soybean in comparison with plants inoculated with the wild-type strain. Finally, transcriptomic analysis showed that, in addition to controlling genes involved in EPS and CG production, motility, and chemotaxis, HH103 MucR1 also affects genes included in the nod regulon, which could account for the symbiotic phenotype of $\mathrm{HH} 103$ mucRl with L. burttii.

\section{RESULTS AND DISCUSSION}

Sinorhizobium fredii HH103 harbors two copies of mucR.

Sequence analysis of the genome of $S$. fredii $\mathrm{HH} 103$ revealed the presence of two copies of the $m u c R$ gene (Vinardell et al. 2015; Weidner et al. 2012). One of them, mucRl (SFHH103_00694), is located on the chromosome and encodes a 143-amino acid protein that is 99 and $80 \%$ identical to the MucR and RosR transcriptional regulators from $S$. meliloti 1021 and Rhizobium leguminosarum bv. trifolii, respectively. The second copy, mucR2 (psfHH103d_392), is located on the symbiotic plasmid close to the nodD1 gene and encodes a protein of 142 residues that is $81 \%$ identical to HH103 MucR1. The MucR1 and MucR2 proteins of $S$. fredii $\mathrm{HH} 103$ are $100 \%$ identical to the corresponding proteins recently described in $S$. fredii CCBAU45436 (Jiao et al. 2016). In strain CCBAU45436, MucR2 is not functionally equivalent to MucR1, due to a frameshift mutation.
In order to analyze the roles of HH103 mucRl and mucR2 in free-living conditions and in symbiosis, the following mutants were constructed as described in Supplementary Methods:

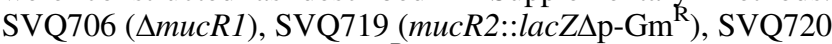

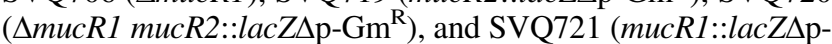
$\mathrm{Gm}^{\mathrm{R}}$ ). A complemented version of SVQ706, called SVQ706C, was constructed by introduction of a wild-type version of the $m u c R l$ gene in cis.

\section{S. fredii HH103 MucR1 is a positive regulator of EPS production.}

The MucR/RosR proteins have been described to be involved in regulation of polysaccharide production in different rhizobia (Janczarek and Skorupska 2011). For this reason, the production of EPS by the different mucR mutants of HH103 was analyzed on yeast extract-mannitol agar (YMA) plates. In $S$. fredii HH103, the presence of flavonoids has a negative effect on EPS production (Acosta-Jurado et al. 2016; Vinardell et al. 2004a). For this reason, production of EPS was investigated both in the absence and in the presence of genistein, an effective nod gene inducer for HH103 (Vinardell et al. 2004b). Regardless of the presence of genistein, all the mutants affected in $m u c R l$ showed a rough appearance, suggesting a drastic reduction in EPS production (Fig. 1). The mucR2 single mutant, instead, was undistinguishable from the wild-type strain, both in the presence or absence of flavonoids. The production of EPS by HH103 $\Delta m u c R 1$ in liquid YM medium was also quantified by the anthrone- $\mathrm{H}_{2} \mathrm{SO}_{4}$ method. These experiments showed that HH103 $\Delta m u c R l$ produced only $17.4 \pm 6.2 \mu \mathrm{g}$ of sugar per milliliter of supernatant in contrast to the $83.2 \pm 16.8 \mu \mathrm{g} / \mathrm{ml}$ produced by the parental strain HH103. The complemented mucRl derivative recovered smooth appearance on YMA plates (Fig. 1) as well as wild-type levels of EPS production $(119.2 \pm 32.5 \mu \mathrm{g} / \mathrm{ml})$. In the presence of genistein, the production of EPS was clearly reduced in the three strains $(6.9 \pm 0.8,4.7 \pm 1.0$, and $6.7 \pm 5.2 \mu \mathrm{g}$ of sugar per milliliter of supernatant for HH103, $\Delta m u c R 1$, and the complemented version of the mutant, respectively).

Production of EPS by HH103 $\triangle m u c R l$ was further analyzed by nuclear magnetic resonance (NMR) spectroscopy. In order to compare NMR spectra from HH103 and HH103 $\Delta m u c R l$, residual signals from a mannan present in culture media were used as reference (Fig. 2, marked with asterisks). Mutant $\Delta m u c R 1$ presented the signals corresponding to wild-type EPS (those corresponding to the anomeric region [zoomed on the left in Figure 2] and those corresponding to acetyl and pyruvate groups), but the intensity of the signals in the mutant was very weak in comparison with those of HH103, confirming that the absence of MucR1 led to a drastic decrease in the production of this polysaccharide. Introduction of a wild-type copy of mucRl restored wild-type levels of EPS production. These results confirmed that MucR1 is a positive regulator of EPS production in $S$. fredii $\mathrm{HH} 103$, in agreement with previous results in S. meliloti 1021, Rhizobium

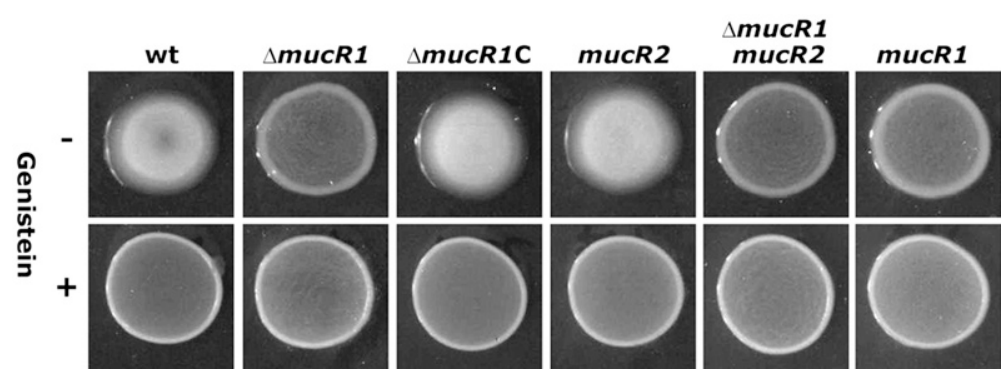

Fig. 1. Colony appearance on yeast extract-mannitol agar (YMA) plates by Sinorhizobium fredii HH103 Rif ${ }^{\mathrm{R}}$ (wt) and different $m u c R 1$ or $m u c R 2$ derivatives in the absence (upper row) or the presence (bottom row) of genistein. The mucRl deletion is denoted as $\Delta m u c R l$, whereas mutations constructed by fusions to the lac $Z \Delta \mathrm{p}-\mathrm{Gm}^{\mathrm{R}}$ cassette are denoted as mucRl or mucR2. The complemented version of the $\Delta m и c R 1$ mutants is indicated as $\Delta m и c R 1 \mathrm{C}$. 
leguminosarum bv. trifolii Rt24.2, and S. fredii CCBAU45436 (Janczarek 2011; Jiao et al. 2016). Our results also show that HH103 MucR2 has no role in EPS production, which is in coherence with the fact that this protein is $100 \%$ identical to the nonfunctional MucR2 protein of $S$. fredii CCBAU45436 (Jiao et al. 2016).

\section{Inactivation of $S$. fredii $m u c R 1$ affects}

\section{biofilm formation ability and autoaggregation.}

As inactivation of $m u c R l$ led to a dramatic decrease of EPS production by $\mathrm{HH} 103$, we investigated whether it could also affect the ability of this strain to form biofilms. For this purpose, $\mathrm{HH} 103$, its $\Delta m u c R 1$ mutant, and the complemented derivative of this mutant were grown in MGM medium (O'Toole and Kolter 1998) in polystyrene microtiter plates. Formation of biofilms was investigated both in the absence and in the presence of genistein (Supplementary Fig. S1). The biomass of the biofilm was measured by staining with crystal violet as described below. The amount of biofilm formed by HH103 $\Delta m u c R l$ was significantly higher than that of the parental strain and was not affected by the presence of genistein. The same results were obtained with the $m u c R 1:: l a c Z \Delta \mathrm{p}-\mathrm{Gm}^{\mathrm{R}}$ and with the double mucR1 mucR2 mutant (data not shown). The introduction of a wild-type copy of $m u c R I$ in the $\Delta m u c R l$ mutant restored normal levels of biofilm formation. The increased ability for biofilm formation exhibited by HH103 $\Delta m u c R 1$ was surprising, since, in previous works, we have shown that EPS is an important trait for biofilm formation by $S$. fredii HH103 (Acosta-Jurado et al. 2016; RodríguezNavarro et al. 2014). In addition, in the microtiter wells inoculated with the $\Delta m u c R l$ mutant (especially in the cultures grown in the absence of genistein), a floating and translucent layer was observed. Thus, the increased biofilm formation capacity exhibited by HH103 $\Delta m u c R l$ appears to correspond to the formation of an aggregate of cells in the liquid-air interface (also called pellicle) rather than to a biofilm of cells attached to the liquid-covered plastic surface of the well.

The effect of mucRl inactivation on biofilm formation was also investigated on glass surfaces. For this purpose, plasmid
pSKDSRED (Kelly et al. 2013), containing a constitutively expressed red fluorescent protein, was introduced by conjugation into HH103, its $\Delta m u c R 1$ derivative, and the complemented version of this mutant $(\triangle m u c R l C)$, and the resultant strains were grown in MGM medium in glass Coplin staining jars containing glass slides (discussed below; Supplementary Fig. S2). The biofilms formed on glass slides were scored at 24 and $96 \mathrm{~h}$ postinoculation by epifluorescence microscopy. Three different sections of the glass slide were examined, lower, medium, and upper, located at 5, 28, and $49 \mathrm{~mm}$ from the bottom of the slide, respectively. Thus, the lower and medium sections were sunken into the culture medium, whereas the upper section was located at the liquid-air interface. Results, presented in Supplementary Fig. S3 and Figure 3, revealed that the $\Delta m u c R 1$ mutant showed increased attachment with respect to both $\mathrm{HH} 103$ and $\Delta m u c R l \mathrm{C}$ and that this attachment was localized mostly at the liquid medium-air interface. Thus at $24 \mathrm{~h}$ postinoculation, both $\mathrm{HH} 103$ and $\triangle m u c R l C$ showed a dispersed pattern of attachment in the three sections scored, whereas $\triangle m u c R l$ displayed a layer of cells attached to the upper section. At $96 \mathrm{~h}$ (Fig. 3), this layer of cells was also formed by HH103 and $\Delta m u c R l C$, but it was much more evident for $\Delta m u c R 1$. These results confirmed that the $\Delta m u c R l$ derivative of $S$. fredii $\mathrm{HH} 103$ exhibits increased capacity to form biofilms onto inert surfaces in the liquid-air interface.

We have also analyzed whether the changes promoted by $m u c R l$ inactivation could influence bacterial autoaggregation capacity as described below (Supplementary Fig. S4). After $96 \mathrm{~h}$ of growth in liquid MGM medium with continuous shaking $(180 \mathrm{rpm})$, the three $m u c R l$ mutants tested $(\Delta m u c R 1$, $m u c R l:: l a c Z \Delta \mathrm{p}-\mathrm{Gm}^{\mathrm{R}}$, and the double mucRl mucR2 mutant) showed elevated autoaggregation capacities $(90.0 \pm 3.1,76.4 \pm$ 4.8 , and $87.6 \pm 1.7 \%$ respectively), in clear contrast to the wild

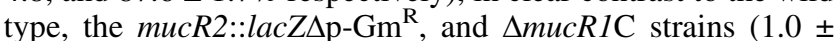
$0.7,1.1 \pm 0.7$, and $2.7 \pm 3.0 \%$, respectively). In order to check whether the decreased production of EPS exhibited by the different mucRl mutants of HH103 could be the reason for the increased autoaggregation capacity observed in these mutants, strain SVQ530, an exoA::lacZAp-Gm ${ }^{\mathrm{R}}$ EPS-defective mutant of

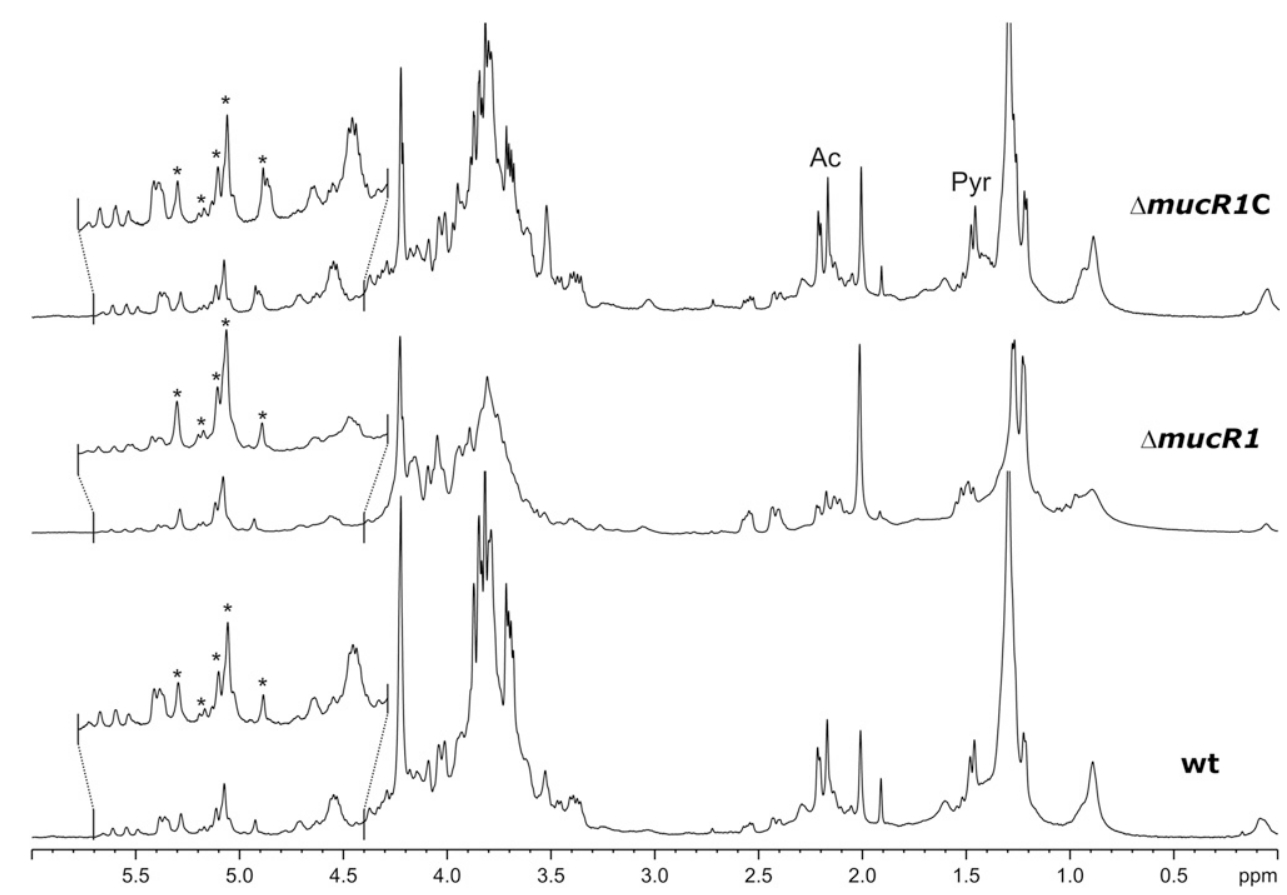

Fig. 2. Nuclear magnetic resonance $\left({ }^{1} \mathrm{H}-\mathrm{NMR}\right)(500 \mathrm{MHz}, 353 \mathrm{~K})$ spectra of exopolysaccharide (EPS) isolated from Sinorhizobium fredii HH103 Rif ${ }^{\mathrm{R}}$ (marked as wt), HH103 $\triangle$ тисR1, and HH103 $\triangle m и с R 1 \mathrm{C}$. Signals from acetyl (Ac) and pyruvate (Pyr) groups are indicated. Signals corresponding to the anomeric region of EPS are zoomed on the left. Residual signals from a mannan present in culture media were used as reference (marked with asterisks). 
HH103, was also included in these studies, showing an intermediate autoaggregation capacity $(29.4 \pm 1.3 \%)$, which was significantly different $(P$ value $<0.05)$ from those of the wild type and the $\triangle m u c R l$ mutant strains. Thus, our results indicate that $m u c R l$ inactivation results in an increased autoaggregation capacity of HH103, which is in agreement with the results, reported by Rachwał et al. (2015), for a RosR mutant of $R$. leguminosarum bv. trifolii. To elucidate whether this increase in autoaggregation depends only on a decrease in EPS or also in additional bacterial traits requires further investigation.

\section{Inactivation of $S$. fredii mucRI does not affect}

lipopolysaccharide (LPS), K-antigen polysaccharide

(KPS), and intracellular CG production

but enhances secretion of external CG.

In rhizobia, several genes are involved in the production of more than one surface polysaccharide. For example, the $S$. fredii $r k p-3$ region is involved in both KPS and LPS synthesis (Margaret et al. 2012). Because of this, we decided to investigate whether mucR1, mucR2, or both could affect the production of other surface polysaccharides in $S$. fredii HH103. For this purpose, both LPS- and KPS-enriched fractions of bacterial crude extracts from HH103 and its $\Delta m u c R 1$, mucRl::lacZ $\Delta \mathrm{p}-\mathrm{Gm}^{\mathrm{R}}$, mucR2::lacZ $\Delta \mathrm{p}-\mathrm{Gm}^{\mathrm{R}}$, and $\Delta m u c R 1$ mucR $2:: l a c Z \Delta \mathrm{p}-\mathrm{Gm}^{\mathrm{R}}$ derivatives were prepared and were analyzed by polyacrylamide gel electrophoresis (PAGE). As shown in Supplementary Fig. S5, the LPS and KPS electrophoretic profiles of all the mutants tested were undistinguishable from those of the parental strain HH103. These results are in contrast to those reported by Janczarek et al. (2010), who found that rosR inactivation affected LPS O-antigen composition in $R$. leguminosarum bv. trifolii.

S. fredii HH103 $\Delta m u c R l$ bacterial crude extracts were also analyzed by ${ }^{1} \mathrm{H}-\mathrm{NMR}$, which provides structural information about KPS and internal CG (Supplementary Fig. S6), showing that inactivation of $m u c R l$ did not affect the production of these polysaccharides in $S$. fredii $\mathrm{HH} 103$.

On the other hand, the ${ }^{1} \mathrm{H}-\mathrm{NMR}$ analysis of extracellular polysaccharides produced by HH103 $\triangle m u c R l$ revealed that this strain, in addition to a decreased EPS production, showed higher amounts of extracellular CG than the parental strain HH103 (Fig. 4, signals shaded in gray). Complementation of the mutation led to wild-type levels of external CG. In order to elucidate whether this phenomenon was specifically due to $m u c R l$ inactivation or was a consequence of reduction of EPS production, supernatants of $\mathrm{HH} 103$ exoA were also analyzed by ${ }^{1} \mathrm{H}-\mathrm{NMR}$ (Fig. 4). The exoA mutant of HH103 also exhibits enhanced production of external CG, suggesting that, in HH103 $\Delta m u c R l$, this phenotype might be an indirect effect of the diminution of EPS synthesis.

\section{MucR1 is an important regulator of symbiosis of $S$. fredii HH103 with Glycine max cv. Williams and Lotus burttii.}

In previous investigations, the inactivation of $m u c R$ orthologs showed different effects on symbiosis depending on the host plants (Janczarek et al. 2009, 2010; Keller et al. 1995). A mucR mutant of $S$. meliloti was not affected in symbiosis with Medicago spp., whereas inactivation of the $R$. leguminosarum bv. trifolii mucR ortholog $(\operatorname{ros} R)$ led to a significant decrease in nodule number and nitrogen fixation with Trifolium plants. In this work, we decided to investigate the symbiotic effect of the mutation of HH103 in mucRl on symbiosis with two host legumes, Glycine max (the American variety Williams) and Lotus burttii (Margaret et al. 2011; Sandal et al. 2012). It is worthwhile to note that $S$. fredii HH103 infects these two host plants by different mechanisms, i.e., infection threads in soybean and crack-entry with Lotus burttii (A. Acosta-Jurado, D. N. Rodríguez-Navarro, Y, Kawaharada, J. Fernández Perea, A. Gil Serrano, H. Jin, Q. An, M. A. Rodríguez-Carvajal, S. U. Andersen, N. Sandal,
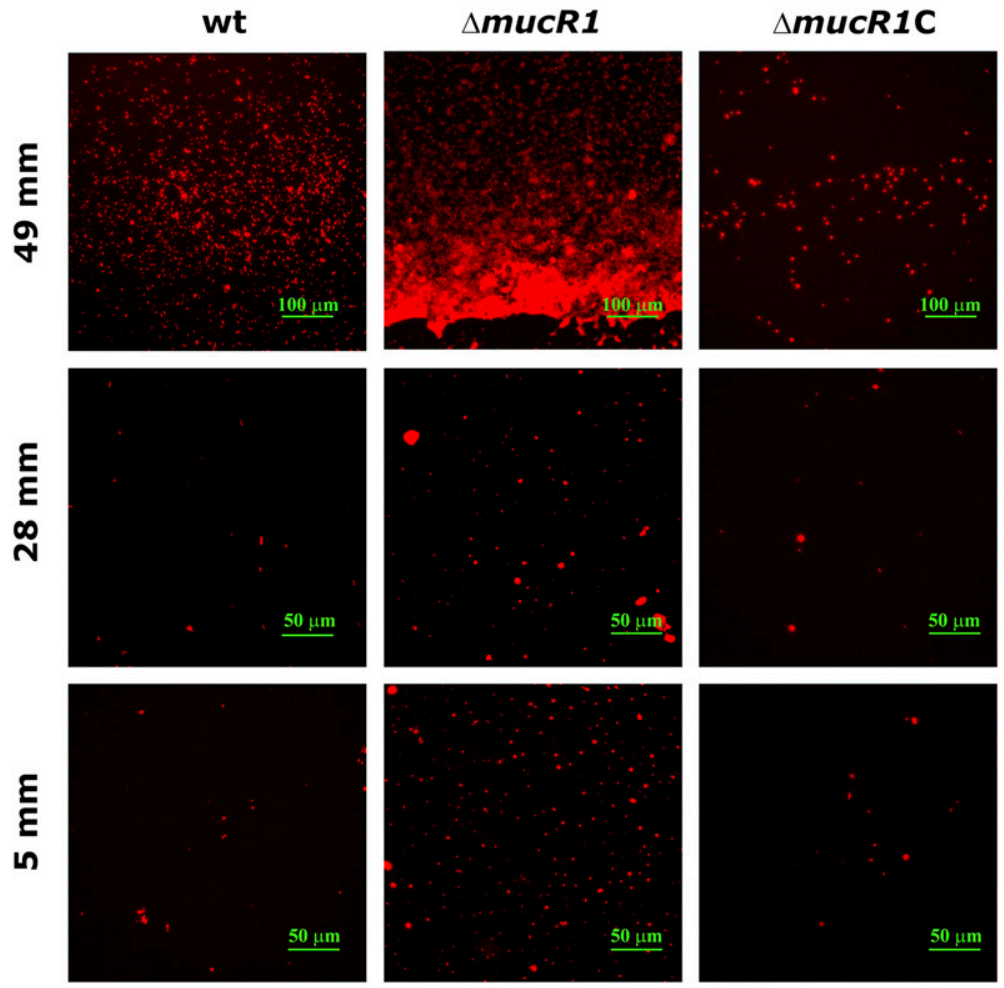

Fig. 3. Biofilm formation ability of Sinorhizobium fredii $\mathrm{HH} 103 \mathrm{Rif}^{\mathrm{R}}(\mathrm{wt})$, its $m u c R 1$ derivative $(\Delta m u c R 1)$, and the complemented version of this mutant ( $\triangle$ mисR1C) harboring plasmid pSKDSRED on glass slides after $96 \mathrm{~h}$ of growth in MGM (O'Toole and Kolter 1998) medium. The amount of biofilm can be estimated as the fluorescence emitted by the attached bacterial population. Photos were taken at different heights of the glass slide (as indicated on the left), using Nikon Eclipse Ti-U epifluorescence microscopy with an excitation and emission wavelength of 554 and $586 \mathrm{~nm}$, respectively. 
J. Stougaard, J. M. Vinardell, and J. E. Ruiz-Sainz, unpublished; Margaret et al. 2011). Additionally, the $m u c R 2$ and the double mucR1 mucR2 mutants were also tested in soybean. Results presented in Tables 1 and 2 show that, in $S$. fredii HH103, inactivation of $m u c R l$ led to a severe impairment of symbiotic effectiveness with the two legumes tested. In fact, in both cases, plant shoot weights of plants inoculated with HH103 $\Delta m u c R I$ were not different from those of noninoculated plants. On the other hand, inactivation of $m u c R 2$ did not affect the symbiotic

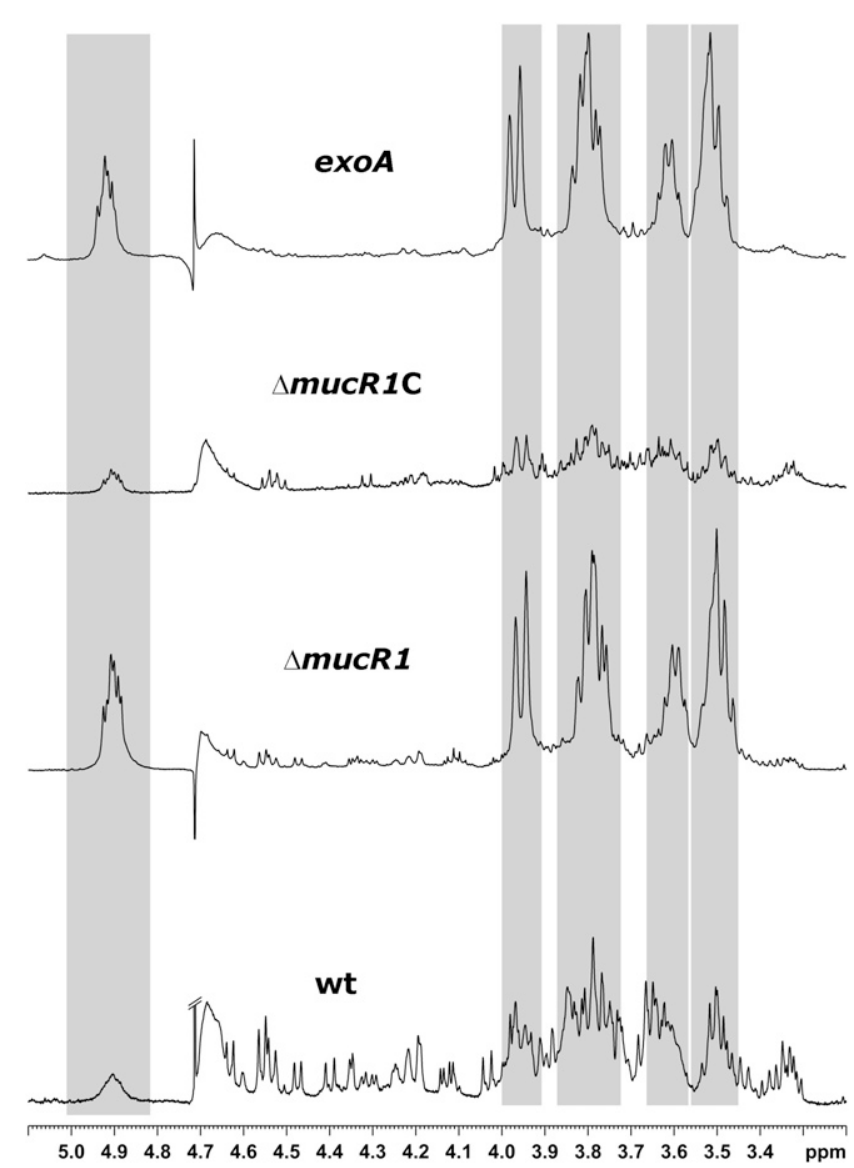

Fig. 4. Nuclear magnetic resonance $\left({ }^{1} \mathrm{H}-\mathrm{NMR}\right)(500 \mathrm{MHz}, 303 \mathrm{~K})$ spectra of fractions containing cyclic glucans (CG) after isolation from Sinorhizobium fredii $\mathrm{HH} 103 \mathrm{Rif}^{\mathrm{R}}$ (marked as wt), HH103 $\Delta$ mисR1, HH103 $\Delta$ mисRlC, and an exoA derivative of $\mathrm{HH} 103$. Signals from $\mathrm{CG}$ are shaded in gray.

Table 1. Responses of Glycine $\max \mathrm{cv}$. Williams to inoculation with Sinorhizobium fredii $\mathrm{HH} 103$ and its mucR 1 and $m u c R 2$ derivatives $^{\mathrm{a}}$

\begin{tabular}{|c|c|c|c|}
\hline Inoculant $^{b}$ & $\begin{array}{l}\text { Nodule } \\
\text { number }\end{array}$ & $\begin{array}{c}\text { Nodule fresh } \\
\text { weight (mg) }\end{array}$ & 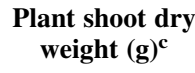 \\
\hline HH103 Rif ${ }^{\mathrm{R}}$ & $58.4 \pm 10.6$ & $834.6 \pm 208.6$ & $2.55 \pm 0.74$ \\
\hline HH103 $\Delta m и с R 1$ & $126.2 \pm 49.0 *$ & $766.6 \pm 268.0$ & $1.20 \pm 0.42 *$ \\
\hline HH103 $\Delta т и с R 1 \mathrm{C}$ & $52.6 \pm 12.2$ & $792.6 \pm 147.1$ & $2.74 \pm 0.78$ \\
\hline $\begin{array}{l}\text { HH103 mисR2:: } \\
\text { lacZ-Gm } \\
\text { HH103 } \Delta \text { тисR1 }\end{array}$ & $60.4 \pm 6.7$ & $829.2 \pm 168.7$ & $2.33 \pm 0.97$ \\
\hline mucR2::lacZ-Gm ${ }^{\mathrm{R}}$ & $118.8 \pm 21.6^{*}$ & $749.2 \pm 39.9$ & $1.54 \pm 0.41^{*}$ \\
\hline
\end{tabular}

${ }^{a}$ Data represent averages of five Leonard jars, each one containing two soybean plants. Determinations were made 42 days after inoculation. All the treatments were individually compared with the values of the parental strain, using the nonparametric test of Mann-Whitney. The presence of an asterisk denotes a significant difference with a $P$ value $<0.05$.

b Bacteria isolated from 12 nodules formed by each inoculant showed the expected resistance markers.

${ }^{\mathrm{c}}$ Plant shoot dry weight of noninoculated plants was $1.24 \pm 0.21 \mathrm{~g}$ per jar. performance of $S$. fredii HH103 with soybean 'Williams'. The double mucRl mucR2 mutant exhibited the same phenotype as the $\Delta m u c R l$ mutant. The complemented derivative of $\mathrm{HH} 103$ $\Delta m u c R l$ was undistinguishable from the parental strain $\mathrm{HH} 103$ in the different parameters tested in their interaction with both soybean and L. burttii.

Strikingly, the nodule numbers induced by the $\Delta m u c R l$ mutant were significantly higher with soybean but significantly lower with $L$. burttii, if compared with the nodule numbers induced by the parental strain. Acetylene reduction assays revealed that, in the case of soybean nodules, nitrogenase activity of the $\triangle m u c R l$ derivative was ten-fold reduced with respect to that of the parental strain $(309.8 \pm 20.2$ and 3,424.7 \pm 971.2 nmoles ethylene per plant per hour, respectively). In L. burttii, the reduction of nitrogenase activity due to $m u c R l$ inactivation was less pronounced $(95.0 \pm 27.7$ versus $295.6 \pm 80.8)$.

During the preparation of this manuscript, an article describing the symbiotic role of the $S$. fredii CCBAU45436 mucRl and $m u c R 2$ genes in their interaction with the Asiatic variety of Glycine max JD17 was published (Jiao et al. 2016). Jiao et al. (2016) found that inactivation of $m u c R l$ led to increased nodulation with this soybean variety but, also, to a dramatic impairment in nitrogen-fixation activity. The $m u c R 2$ derivative of CCBAU45436 was not affected in its interaction with soybean JD17. Thus, our results are in agreement with those reported by Jiao et al. (2016), showing that, in $S$. fredii strains, mucRl but not $m u c R 2$ is essential in the interaction with both Asiatic (as JD17) or commercially improved American (as 'Williams') varieties of soybean. In addition, our work shows that $m u c R l$ is also essential for HH103 symbiosis with another legume, L. burttii. However, in this legume, the symbiotic defect (a decrease in both nodule number and nitrogen fixation) appears to be different from that of the interaction of $S$. fredii with soybean and similar to that described for the ros $R$ mutant of $R$. leguminosarum bv. trifolii with Trifolium spp. (Janczarek et al. 2010).

\section{S. fredii HH103 MucR1 represses its transcription by binding to its own promoter.}

Previous results have demonstrated that $S$. meliloti mucR and $R$. leguminosarum bv. trifolii ros $R$ are negatively autoregulated (Janczarek and Skorupska 2007; Keller et al. 1995). In this work, we studied whether $S$. fredii HH103 MucR1 has an effect on its own transcription. A 408-bp fragment containing the upstream sequence of the mucRl gene as well as its start codon was fused to the $e g f p$ gene (coding for an enhanced version of the green fluorescent protein) present in plasmid pPHU231 (discussed below), which allows mucRl expression to be analyzed by measurement of fluorescence. The resultant plasmid, called pMUS1196, was introduced in both $S$. fredii HH103 Rif ${ }^{\mathrm{R}}$ and its $\triangle m u c R l$ derivative. In the $m u c R l$ mutant background, GFP expression (the ratio of fluorescence to optical density at

Table 2. Responses of Lotus burttii to inoculation with Sinorhizobium fredii $\mathrm{HH} 103$ and its mucRl derivative ${ }^{\mathrm{a}}$

\begin{tabular}{lcr}
\hline Inoculant $^{\mathbf{b}}$ & Nodule number & $\begin{array}{c}\text { Plant shoot fresh } \\
\text { weight }(\mathbf{m g})^{\mathbf{c}}\end{array}$ \\
\hline HH103 Rif & $78.5 \pm 20.6$ & $1180.8 \pm 386.8$ \\
HH103 $\Delta$ тисR1 & $42.4 \pm 12.9^{*}$ & $235.2 \pm 36.2^{*}$ \\
HH103 $\Delta$ тисR1C & $70.0 \pm 14.8$ & $973.1 \pm 379.5$ \\
\hline
\end{tabular}

${ }^{a}$ Data represent averages of at least four jars containing four plants each Determinations were made 56 days after inoculation. All the treatments were individually compared with the values of the parental strain, using the nonparametric test of Mann-Whitney. The presence of an asterisk denotes a significant difference with a $P$ value $<0.05$.

b Bacteria isolated from 12 nodules formed by each inoculant showed the expected resistance markers.

c Plant shoot fresh-weight of noninoculated plants was $82.6 \pm 27.1 \mathrm{mg}$ per jar. 
$\left.600 \mathrm{~nm}\left[\mathrm{OD}_{600}\right]\right)$ driven by the $m u c R l$ promoter was 3.5 -fold higher $(363.19 \pm 22.01)$ than that measured in the wild-type strain (100.00 \pm 4.39$)$, which suggests that MucR1 acts as a negative autoregulator.

In order to check whether HH103 MucR is able to bind to its own promoter, this protein was fused to GST (glutathione $S$-transferase), was overexpressed in Escherichia coli, was purified, and was used for EMSA (electrophoretic mobility shift assay) studies. As shown in Supplementary Figure S7, $S$. fredii HH103 MucR1 binds to a 399-bp DNA fragment that covers the upstream sequence (from -405 to -7 ) of $S$. fredii $m u c R 1$. When different internal fragments of this sequence were used in EMSA assays, binding of MucR1 was detected to fragments 2 (302 bp, between -405 and -104 , with respect to the start codon) and 3 (271 bp, from -277 to -7), which overlap in 174 nucleotides. Fragment 3 contains a well-conserved MucR-binding (from -50 to -33 ) site, as defined for the $S$. meliloti mucR promoter (Bertram-Drogatz et al. 1997), but this site is not located in the sequence common to fragment 2 . In fact, $S$. fredii MucR1 does not bind to fragment 4 (111 bp, from -117 to -7 ), which contains this putative MucR-binding site. Sequence analysis of the 174-bp sequence common to fragments 2 and 3 showed that it does not contain any well-conserved MucR- or RosR-binding site. Thus, we have detected binding of MucR1 to its own promoter sequence but, surprisingly, this binding appears not to be dependent on a well-conserved MucR binding site or, maybe, in addition to this site, an unidentified sequence is absolutely required for MucR binding. Similar results were found in S. meliloti, in which Bertram-Drogatz et al. (1998) found that MucR bound to upstream sequences of exoH and exoY but failed to find the consensus sequence previously defined for the mucR promoter (Bertram-Drogatz et al. 1997).

Altogether, our results show that, as expected, $S$. fredii $\mathrm{HH} 103$ MucR1 is a transcriptional regulator that represses its own expression.

\section{$S$. fredii HH103 MucR1 is a global regulator.}

Several studies documented the role of RosR/MucR in regulating different bacterial traits related to interaction with eukaryotic hosts not only in rhizobia but, also, in pathogenic bacteria such as Brucella abortus and B. melitensis (Caswell et al. 2013; Janczarek 2011; Janczarek et al. 2010; Mirabella et al. 2013). We have also found that $S$. fredii HH103 MucR1 affects EPS and external GC production, pellicle formation, autoaggregation, and symbiotic performance with the two host plants tested, soybean and L. burttii. This prompted us to analyze, by transcriptomics, the set of genes whose expression is affected by MucR1 in $S$. fredii HH103. Since the number of nodules induced is significantly affected in the two host plants tested, we decided to perform the analysis in the presence or absence of genistein, an effective nod-inducer flavonoid for HH103 (Vinardell et al. 2004b).

Very recently, transcriptomic studies of the effect of the absence of MucR/RosR in $R$. leguminosarum bv. trifolii Rt24.2 and S. fredii CCBAU45436 (Jiao et al. 2016; Rachwał et al. 2015) have been published. In the former strain, 1,106 genes were differentially expressed in free-living cells of the wild-type strain and its ros $R$ derivative ( $\log _{2}$ of mutant/wild type values $>2$ ). In $S$. fredii CCBAU45436, the numbers of differentially expressed genes (DEG) in the mucRl mutant when compared with the wild-type strain $\left(\log _{2}\right.$ of mutant/wild type values $\left.>1\right)$ were 621 and 597 in free-living cells and in bacteroids isolated from soybean nodules, respectively. The numbers of DEG in HH103 $\triangle m u c R l$ (defined as genes showing a |fold-change| $\geq 3.5$ or $\log _{2}$ of mutant/wild type values > 1.871) were 393 and 904 in the absence and in the presence of genistein, respectively, 265 of them being shared by both conditions (Supplementary Fig. S8; Supplementary Dataset 1). The expression levels of 20 DEG were validated by quantitative reverse transcription-polymerase chain reaction (qRT-PCR) (Table 3). Thus, as previously reported for other rhizobia, HH103 MucR1 appears to be a global regulator affecting the expression of hundreds of genes. Detailed information about global gene expression levels in the wild type and the $\Delta m u c R l$ strains in the absence or presence of genistein as well as the lists of DEG in both conditions are given in Supplementary Datasets 2 to 5 .

\section{S. fredii HH103 MucR1-dependent genes} in the absence of genistein.

In the absence of genistein, 227 and 166 genes were up- and down-regulated, respectively, in HH103 $\Delta m u c R 1$, as compared

Table 3. RNA-Seq data validation using quantitative reverse transcription-polymerase chain reaction (qRT-PCR) ${ }^{\mathrm{a}}$

\begin{tabular}{|c|c|c|c|c|c|}
\hline \multirow[b]{2}{*}{ Locus tag/promoter sequences } & \multirow[b]{2}{*}{ Gene name } & \multicolumn{2}{|c|}{ Absence of genistein } & \multicolumn{2}{|c|}{ Presence of genistein } \\
\hline & & RNA-Seq & qPCR & RNA-Seq & qPCR \\
\hline psfHH103d_118 & & 4.89 & $5.13 \pm 0.07$ & 1.18 & $-1.29 \pm 0.42$ \\
\hline psfHH103d_126/NB8 & $\operatorname{nod} A$ & -1.35 & $-1.23 \pm 0.5$ & -3.60 & $-1.88 \pm 0.28$ \\
\hline psfHH103d_208/NB17 & & 9.31 & $4.38 \pm 0.01$ & -1.51 & $-1.26 \pm 0.17$ \\
\hline psfHH103d_257/NB15 & & 4.54 & $3.27 \pm 0.17$ & -2.05 & $1.11 \pm 0.21$ \\
\hline psfHH103d_373/NB1 & & 9.25 & $11.64 \pm 5.58$ & -1.52 & $-1.17 \pm 0.01$ \\
\hline psfHH103d_391 & mucR2 & 3.46 & $8.68 \pm 4.05$ & 2.16 & $2.54 \pm 0.14$ \\
\hline psfHH103d_448/NB13 & & 7.11 & $4.54 \pm 0.44$ & -1.31 & $1.47 \pm 0.16$ \\
\hline psfHH103d_604 & & -11.25 & $-5.56 \pm 2.16$ & -14.04 & $-9.48 \pm 7.59$ \\
\hline SFHH103_00308 & fliG & 8.04 & $10.26 \pm 5.69$ & 13.75 & $4.41 \pm 1.25$ \\
\hline SFHH103_00335 & rem & 5.16 & $18.02 \pm 1.74$ & 10.33 & $4.29 \pm 0.06$ \\
\hline SFHH103_00387 & $f b p A$ & -70.28 & $-111.75 \pm 26.23$ & -38.44 & $-18.51 \pm 1.54$ \\
\hline SFHH103_01240 & exoR & -4.56 & $-3.28 \pm 1.45$ & -4.59 & $-3.92 \pm 0.08$ \\
\hline SFHH103_02000 & $f t s Z 1$ & 4.80 & $4.98 \pm 0.33$ & 1.67 & $2.60 \pm 0.18$ \\
\hline SFHH103_02172 & $p t s N$ & 9.89 & $40.62 \pm 9.17$ & 6.18 & $17.57 \pm 1.52$ \\
\hline SFHH103_02569 & & 51.34 & $45.0 \pm 17.24$ & 25.69 & $70.65 \pm 7.32$ \\
\hline SFHH103_03584 & & 106.74 & $124.51 \pm 1.29$ & 28.68 & $503.2 \pm 41.76$ \\
\hline SFHH103_05376 & exoA & -2.0 & $-2.53 \pm 1.19$ & -4.09 & $-2.46 \pm 0.19$ \\
\hline SFHH103_05378 & exoK & -2.82 & $-3.03 \pm 0.46$ & -4.13 & $-2.60 \pm 0.1$ \\
\hline SFHH103_05384 & exoY2 & -11.91 & $-4.35 \pm 0.38$ & -8.78 & $-3.90 \pm 0.97$ \\
\hline SFHH103_06390 & & 35.51 & $23.95 \pm 5.25$ & 14.13 & $11.89 \pm 0.5$ \\
\hline
\end{tabular}

a The expression of 20 individual genes was measured in Sinorhizobium fredii HH103 and in a $\Delta m u c R 1$ derivative, both in the presence or absence of genistein. For qRT-PCR, fold change values were calculated using the $\Delta \Delta \mathrm{C}_{\mathrm{t}}$ method (Pfaffl et al. 2002) and were normalized to the reference 16S rRNA. Data represent expression level fold changes in $\mathrm{HH} 103 \Delta m u c R 1$ with respect to HH103. 
with the wild-type strain. Many of the genes affected (174 of 393) code for hypothetical proteins, including the two genes showing the highest fold-changes (SFHH103_03584 and 06391, +106.7 and +98.2 , respectively). In agreement with previous results described for a ros $R$ mutant of $R$. leguminosarum bv. trifolii, the expression of at least 20 transcriptional regulators belonging to different families (such as GntR and LuxR) was altered (either induced or repressed) in the $m u c R l$ background compared with the wild-type strain, indicating that part of the DEG detected might not be directly controlled by MucR1. Among these regulatory elements, it is worthwhile to notice the presence of a Crp/FixK-like transcriptional regulator (psfHH103d_604, foldchange-11.3), which is involved in regulation of a large number of genes for the anoxic and microoxic, endosymbiotic, and nitrogen-fixing life styles of Bradyrhizobium japonicum (Mesa et al. 2008). Other interesting transcriptional regulators found as DEG are members of two-component systems such as the chemotaxis-related genes cheY1 and cheY2 or feuP (discussed below). Also interesting is the fact that two of the genes showing the highest levels of downregulation in HH103 $\Delta m u c R 1$ were hmuS (coding for a hemin transport/degrading protein, fold change -13.5) and $f b p A$ (iron deficiency-induced periplasmic protein, -70.3), suggesting a role for MucR1 in regulation of Fe uptake.

Genes related to the synthesis of surface polysaccharides. Concerning genes related to the synthesis of surface polysaccharides, unexpectedly, most exo genes were not included as DEG, because they were little or not at all affected. This is the case for genes coding for glycosyl transferases putatively involved in the synthesis of the EPS structural subunit, such as exo $A$, exoL, exoM, or exoO (fold-changes of $-2,-2.1,-1.2$, and 1.6, respectively) or exoN and exoB, responsible for the production of UDP-Glc and UDP-Gal, respectively ( -2.8 and -1.9). Similar results have been recently reported for a RosR mutant of Rhizobium leguminosarum bv. trifolii Rt24 (Rachwał et al. 2015). Instead, the exoY2 and exoFlgenes, which are responsible for the addition of the first sugar residue (UDP-Gal) to the lipid carrier located in the internal membrane, and exo $Q$, whose encoded product is involved in EPS polymerization, were more strongly repressed $(-11.9,-5$, and -4.1 respectively). Most probably, these three genes constitute an operon (RodríguezNavarro et al. 2014). Our results are also in agreement with previous observations carried out in $S$. meliloti MucR, which has also a slight effect on exo gene expression but increases the transcription of exoY, exoF, and exo $Q$ (Keller et al. 1995). Surprisingly, the HH103 exoR gene, which codes for a repressor of exo genes, is also repressed (-4.5) in the $\Delta m u c R l$ background.

Other surface component-related genes that are down-regulated in the $m u c R 1$ mutant background are $l p x C$, coding for a UDP-3-Oacyl- $N$-acetylglucosamine deacetylase involved in lipid A biosynthesis, $n d v A$, involved in CG transport from the cytoplasm to the periplasm, and SFHH103_01577, which codes for a CG-modification protein containing the MdoB domain characteristic of phosphoglycerol transferases (fold-changes of $-3.9,-5$, and -6.2 , respectively). Although we have not detected differences between the LPS electrophoretic patterns of HH103 and its $\Delta m u c R l$ derivative, the possibility that the absence of MucR1 could provoke changes in the LPS nondetected by PAGE analyses cannot be discarded. Regarding CG, supernatants of S. fredii HH103 $\Delta m u c R l$ exhibited higher amounts of extracellular CG than those of the parental strain. To our knowledge, there is no information available about how $\mathrm{CG}$ are secreted to the medium, since $n d v A$ is an internal membrane protein involved in the transport of CG from the cytoplasm to the periplasm. On the other hand, at least in $S$. meliloti, external CG appears to be predominantly neutral (Geiger et al. 1991). The fact that both $n d v A$ and SFHH103_01577 (which codes for a putative CG phosphoglycerol transferase) are repressed in HH103 $\triangle m u c R l$ could be related to this enhanced secretion of CG to the medium. We have also demonstrated that a HH103 mutant unable to produce EPS exhibits enhanced CG secretion, suggesting that this phenomenon could be a consequence of depletion in EPS production. However, elucidation of the relationship between EPS and external CG production in $S$. fredii $\mathrm{HH} 103$ requires further investigation. Remarkably, in HH103 $\triangle m u c R l$, the response regulator-encoding gene feuP is down-regulated (-5.4). In $S$. meliloti, this gene controls the transcription of at least 16 genes (including $n d v A$ ) in response to low osmolarity conditions (Griffitts et al. 2008). In addition to $n d v A$, orthologs of seven other genes (all coding for hypothetical proteins) induced by FeuP in $S$. meliloti are also clearly down-regulated in the HH103 $\triangle m u c R l$ background, i.e., SFHH103_00611 (-5.8, ortholog of SMb20838), SFHH103_00710 (-4.7, SMc00065), SFHH103_00740 (-5.2, SMc02389), SFHH103_ 01338 (-8.4, SMc00252), SFHH103_01771 (-5.8, SMc04336), SFHH103_02119 (-5.2, SMc01557), and SFHH103_02145 (-11.0, SMc01586).

Genes involved in motility and chemotaxis. Regarding genes showing upregulation in HH103 $\Delta m u c R 1$ in the absence of genistein, it is worth mentioning the presence of a large set of genes related to chemotaxis and motility. This is in clear contrast to the results recently reported by Rachwat and coworkers (2015) for R. leguminosarum bv. trifolii, in which it was found that RosR positively regulates these genes and, in consequence, bacterial motility but in agreement with the fact that $S$. meliloti MucR represses bacterial motility (Bahlawane et al. 2008). The group of upregulated chemotaxis-related proteins in $\mathrm{HH} 103$ $\triangle m u c R 1$ includes the two-component response regulator receiver proteins CheY1 and CheY2 (fold-changes of +11.1 and +7.3), the chemotaxis signal transduction protein CheW1 (+9.5), the methyltransferase CheR $(+6.3)$, and the putative antisigma regulatory factor CheX (+5.4). Regarding motility-related genes, different $\mathrm{fli}$, flg, fla (including flaC), and mot genes involved in motor activity, flagellum-dependent cell motility process, and regulation or flagellum filament components were up-regulated in the $m u c R l$ derivative. These results prompted us to investigate whether swimming or surface motility could be affected by mucRl inactivation, as described below. Surprisingly, neither swimming $(13.1 \pm 0.6 \mathrm{~mm}$ in HH103 $\triangle m u c R l$ versus $13.5 \pm$ $0.7 \mathrm{~mm}$ in HH103 after $72 \mathrm{~h}$ of incubation) nor surface motility $(14.0 \pm 7.2 \mathrm{~mm}$ versus $12.5 \pm 4.0 \mathrm{~mm}$ after $72 \mathrm{~h}$ of incubation) were significantly affected in the $\mathrm{HH} 103$ mucR 1 derivative under our experimental conditions, indicating that the biological significance of the upregulation in this strain of such a high number of genes related to motility requires further investigation.

Genes belonging to the nod regulon. Interestingly, many genes located on the symbiotic plasmid and whose expression is dependent on NodD1 and genistein, since they are driven by nod boxes (NB) (Vinardell et al. 2015; Pérez-Montaño et al. 2016), are also up-regulated (fold-change $>3.5$ ) in HH103 $\Delta m u c R 1$ in the absence of flavonoids (Table 4), i.e., psfHH103d_373,_372 (NB1, putatively involved in hopanoid synthesis, fold-changes +9.2 and $+8.5)$, psfHH103d_118, _116 (NB9, hypothetical proteins, +4.9 and +3.5), psfHH103d_448,_447 (NB13, hypothetical proteins, +7.1 and +4.0), psfHH103d_229,_228, _225 (NB14, hypothetical proteins putatively involved in electron transfer to nitrogenase, +8.1 to +4.5), psfHH103d_257 (NB15, histidinolphosphate aminotransferase involved in indole acetic acid production, +4.8), and psfHH103d_208 (NB17, hypothetical ABC-type transporter, +9.3). In addition, two genes whose expression is dependent on $t t s$ boxes are also up-regulated in the $\Delta m u c R l$ background in the absence of genistein, namely, a component of the symbiotic T3SS (psfHH103d_335, TB8, NopX, +4.0) and one of the effectors secreted through this apparatus (psfHH103d_349, TB11, NopP, +3.9). Since the role 
of most of these proteins remains to be elucidated, it is difficult to understand the biological significance of their regulation by MucR1. However, it has been reported that inactivation of HH103 nopP improved symbiotic performance with soybean (López-Baena et al. 2009), which suggests that overexpression of this gene might affect this interaction negatively.

The presence of genistein increases the number of DEG in $H H 103 \Delta$ mucR1. In the presence of genistein, the number of DEG found in HH103 $\Delta m u c R l$ was 904, which is 2.3-fold higher than that detected in the absence of this flavonoid. The fact that the numbers of up- and down-regulated genes were 615 and 289 , respectively, indicates that MucR1 acts mainly as a repressor. A total of 265 genes were differentially expressed in the $\Delta m u c R I$ mutant both in the presence or absence of genistein. Supplementary Dataset 6 contains the list of these genes as well as their expression fold changes in HH103 $\triangle m u c R l$ in both conditions (absence or presence of genistein). For all 265 genes, the sign (positive or negative) of their differential expression was the same in both conditions.

Genes related to surface polysaccharide production, motility, and chemotaxis. In the presence of genistein, genes related to EPS, periplasmic anionic CG production, flagella formation, or chemotaxis were also affected, which suggests that the regulatory effect of MucR1 in these bacterial traits is not dependent on the presence of flavonoids. Although there are additional exo genes
(exoA, exoL, exoK, exoU, exoB, fold changes varying between -3.6 and -4.3 ) that appear as downregulated in the mucRl mutant in the presence of genistein, these genes are also slightly repressed in the absence of genistein (ranging between -2 and -2.8). Regarding genes related to motility, it is worthwhile to note that the flgA gene (coding for a putative periplasmic chaperone that assists in the formation of the flagellar $\mathrm{P}$ ring) is 111.0 overexpressed in the mucRl mutant, as compared with the wildtype strain, in the presence of genistein, in contrast to a 2.8 -fold induction in the absence of flavonoids. However, this difference could be an overestimation due to the fact that transcription of this gene was very low in the wild-type strain in the absence of genistein but not detected at all in the presence of the flavonoid. Other motility-related genes that were more highly expressed in the mucRl mutant in the presence of flavonoid were fliL (flagellar transmembrane protein, +7.3 versus +2.3 ) and the flagellar motor protein-coding genes $\operatorname{mot} B(+17.2$ versus +2.9$)$ and $\operatorname{mot} C$ $(+15.2$ versus +3.1$)$. Remarkably, in the presence of genistein, these three genes are repressed in the wild-type strain (fold changes $-2.9,-2.6$, and -2.0 , respectively), suggesting a complex regulation of motility-related genes in $S$. fredii $\mathrm{HH} 103$. We plan to study further the effect of flavonoids and the role of mucRl in HH103 motility and chemotaxis abilities in the near future.

Genes belonging to the nod regulon. Most of the NB-depending genes that were found overexpressed in the $\Delta m u c R l$ mutant in the

Table 4. Effect of $m u c R l$ inactivation on the expression of the nod regulon in the absence or presence of genistein

\begin{tabular}{|c|c|c|c|c|}
\hline \multirow[b]{2}{*}{$\mathbf{N B}^{\mathbf{a}}$} & \multirow[b]{2}{*}{ Locus-tag (gene name) } & \multirow[b]{2}{*}{ Description } & \multicolumn{2}{|c|}{ Fold change $^{b}$} \\
\hline & & & Without genistein & With genistein \\
\hline \multirow[t]{5}{*}{ NB 1} & psfHH103d_373 & Hypothetical protein (putative steroid Delta-isomerase) & +9.2 & -1.5 \\
\hline & psfHH103d_372 & Squalene/phytoene synthase & +8.5 & -1.2 \\
\hline & psfHH103d_371_5 (hpnD) & Putative squalene/phytoene synthase & +2.6 & +1.3 \\
\hline & psfHH103d_371 & Flavoprotein oxidoreductase & +2.2 & +1.7 \\
\hline & psfHH103d_370 (shc) & Squalene-hopene cyclase & +1.8 & +1.3 \\
\hline \multirow[t]{3}{*}{ NB2 } & psfHH103d_381 (nodZ) & Nod factor fucosyl transferase & -3.0 & -3.3 \\
\hline & psfHH103d_380 (noeL) & $\begin{array}{l}\text { GDP-D-mannose dehydratase (involved in the synthesis of } \\
\text { GDP-L-fucose for Nod factor decoration) }\end{array}$ & +1.1 & -1.5 \\
\hline & psfHH103d_379 (nolK) & $\begin{array}{l}\text { NAD-dependent nucleotide sugar epimerase/dehydrogenase } \\
\text { (involved in the synthesis of GDP-L-fucose for Nod } \\
\text { factor decoration) }\end{array}$ & +1.6 & +1.1 \\
\hline NB3 & psfHH103d_384 & Hypothetical protein & +3.0 & +1.3 \\
\hline \multirow{7}{*}{ NB8 } & psfHH103d_126 (nodA) & Nod factor acyl-transferase & -1.3 & -3.6 \\
\hline & psfHH103d_127 (nodB) & Nod factor deacetylase & -1.1 & -2.5 \\
\hline & psfHH103d_128 (nodC) & Nod factor backbone synthetase & -1.2 & -1.4 \\
\hline & psfHH103d_129 (nodI) & Nod factor export ATP-binding protein & +1.2 & +1.0 \\
\hline & psfHH103d_130 (nodJ) & Nod factor ABC-transporter permease & +1.0 & +1.0 \\
\hline & psfHH103d_131 (nolO') & Nod factor carbamoyl transferase (truncated) & +1.6 & +1.3 \\
\hline & psfHH103d_132 (noeI) & Nod factor fucose methylase & +1.6 & +1.5 \\
\hline \multirow[t]{2}{*}{ NB9 } & psfHH103d_118 & Conserved hypothetical protein & +4.9 & +1.2 \\
\hline & psfHH103d_116 & Hypothetical protein (putative dehydrogenase) & +3.5 & +1.4 \\
\hline NB10 & psfHH103d_161 (psiB) & Conserved hypothetical protein (polysaccharide inhibition?) & +3.1 & -1.7 \\
\hline \multirow[t]{2}{*}{ NB13 } & psfHH103d_448 & Hypothetical protein containing a REC domain & +7.1 & -1.3 \\
\hline & psfHH103d_447 & Conserved hypothetical protein & +4.0 & +1.6 \\
\hline \multirow[t]{6}{*}{ NB14 } & psfHH103d_229 & Putative iron-sulfur cluster assembly accessory protein & +8.1 & -1.4 \\
\hline & psfHH103d_228 & Hypothetical protein & +6.1 & -1.4 \\
\hline & psfHH103d_227 (fixA) & Electron transfer flavoprotein beta subunit & +2.2 & -1.6 \\
\hline & psfHH103d_226 (fixB) & Electron transfer flavoprotein alpha subunit & +2.4 & -1.9 \\
\hline & psfHH103d_225 (fixC) & Oxidoreductase & +4.5 & -1.2 \\
\hline & psfHH103d_224 (fixX) & Ferredoxin-like protein & +3.1 & -1.2 \\
\hline NB15 & psfHH103d_257 $(y 4 w E)$ & Indole Acetic Acid (IAA) biosynthesis & +4.8 & -2.1 \\
\hline NB17 & psfHH103d_208 & Hypothetical protein (ABC-type transport) & +9.3 & -1.5 \\
\hline \multirow[t]{4}{*}{ NB18 } & psfHH103d_323 (ttsI) & Transcriptional activator of the T3SS & +2.1 & -1.9 \\
\hline & psfHH103d_324 (rhcC2) & Component of the T3SS apparatus & +1.5 & +1.3 \\
\hline & psfHH103d_325 & Conserved putative lipoprotein & +1.5 & +2.7 \\
\hline & psfHH103d_326 & Transposase & -1.3 & -1.2 \\
\hline \multirow[t]{3}{*}{ NB19 } & psfHH103d_367 (syrM) & Transcriptional regulator of symbiotic genes & +2.2 & -1.4 \\
\hline & psfHH103d_368 & Hypothetical protein containing an HTH domain & -1.3 & -2.3 \\
\hline & psfHH103d_369 & Hypothetical protein (putative ACC deaminase, partial) & +1.0 & -1.9 \\
\hline
\end{tabular}

\footnotetext{
${ }^{\mathrm{a}} \mathrm{NB}=\operatorname{nod}$ box, according to Vinardell et al. (2015)

$\mathrm{b}$ Fold induction of mucRl mutant versus wild type.
} 
absence of flavonoids are not included in the list of DEG in the presence of genistein, indicating that when NodD1 is activated with flavonoids, the repressor effect of MucR1 on these genes is less pronounced (Table 4). Curiously, in the presence of genistein, the $\operatorname{nod} A$ gene is repressed in the $\Delta m u c R l$ mutant (fold change -3.6), maybe because the expression of nodDl is also slightly reduced $(-1.5)$. In order to further analyze this result, plasmid pMP240, which harbors a copy of the promoterless lacZ gene fused to the Rhizobium leguminosarum nodA promoter (de Maagd et al. 1988), was introduced in $\mathrm{HH} 103$ and its $\Delta m u c R l$ derivative. In the presence of genistein, $\beta$-galactosidase activity (Miller units) of HH103 $\triangle m u c R l$ (pMP240) was significantly lower than that of HH103 (pMP240) $(7,298 \pm 3,306$ versus $23,345 \pm 3,977)$, confirming that the absence of MucR1 has a negative impact on nodA expression in $S$. fredii $\mathrm{HH} 103$. This positive effect of MucR1 on nodD and, therefore, nodABC expression has been previously described in S. meliloti (Mueller and González 2011). Remarkably, nodZ, which is also involved in Nod factor synthesis, is down-regulated (fold change -3.3) in the $\Delta m u c R l$ background in the presence of genistein (Table 4). Taken together, our results suggest that MucR1 is another important regulator in symbiosis, modulating positively or negatively the expression of different genes belonging to the nod regulon. This fact might be related with the phenotype, a clear reduction in symbiotic effectiveness, exhibited by HH103 $\triangle m u c R l$ with the two host legumes analyzed in this work.

In order to better understand the connection between MucR1 and the HH103 nod regulon, we looked for MucR- or RosRbinding boxes in the upstream sequences of all the HH103 nod box-driven genes. This search, which was carried out by using the fuzznunc utility from the EMBOSS software package (Rice et al. 2000), gave no results.

Genes related to inorganic ions transport. As mentioned before, Jiao and coworkers (2016) have very recently described the symbiotic phenotype of a $m u c R l$ derivative of $S$. fredii CCBAU45436 with soybean JD17. As we have found for HH103 $\triangle m u c R 1$ with soybean 'Williams', CCBAU45436 mucRl induces the formation of a higher number of nodules than the wildtype strain and these nodules exhibit a severe impairment in nitrogen-fixation capacity. In that work, the authors found that the expression of several ion transporters is down-regulated in bacteroids of a mucRl mutant. This might account for the reduction of nitrogen-fixation capacity of this mutant in soybean JD17 nodules. In our study, none of the transporter-encoding genes studied by Jiao et al. (2016) was induced by flavonoids in the wild-type strain and only a few of them were affected in the mucRl mutant. In the absence of genistein, ssuAC and tauB (involved in aliphatic and aminoethane sulphonate transport) were overexpressed (fold changes of $+7.3,+4$, and +3.5 ) in the mucRl derivative. In the presence of genistein, $\bmod A$ and $\bmod C$ (related to molybdenum transport) were, strikingly, repressed $(-4.8)$ and induced (+4.7), respectively, in HH103 $\Delta m u c R l$, whereas phoC (phosphate transport) was induced (+4.3). Thus, our results indicate that the downregulation of different ion transporters caused by the lack of MucR1 observed in strain CCBAU45436 in the bacteroid state does not take place in freeliving cells, even in the presence of inducing flavonoids.

\section{Conclusions and perspectives.}

The rhizobia-legume symbiosis involves a complex molecular dialogue that has to be finely regulated. On the bacterial part, recent studies reveal that the number of genes symbiotically related is higher than expected (Huyghe et al. 2015; Jiao et al. 2016; Lang et al. 2008; Pérez-Montaño et al. 2016) and that their regulation involves the participation of a number of transcriptional regulators. In addition to NodD, TtsI, and SyrM, global regulators such as NolR and MucR also play a role in this process. $S$. fredii strains, in contrast to $S$. meliloti or $R$. leguminosarum, harbor two copies of the zinc-finger transcriptional regulator MucR, although only MucR1 appears to be functional in strains CCBAU45436 and HH103, due to a frameshift mutation in the $3^{\prime}$ end of $m u c R 2$ (Jiao et al. 2016). In this work, we have demonstrated that $S$. fredii HH103 MucR1 is a global regulator that affects the transcription of hundreds of genes, including those related to EPS production and CG export, and, in addition, is clearly connected to the nod regulon. In consequence, inactivation of mucRl not only affects free-living cells but, also, has negative consequences on symbiotic interaction. Remarkably, the HH103 MucR1 regulator affects differently symbiosis depending on the host plant. Thus, when this protein is absent, the interaction with $L$. burttii is negatively affected in both nodule number and nitrogen fixation, whereas, with 'Williams', soybean nodule number is increased, although nitrogen fixation is dramatically decreased, indicating that MucR 1 is essential for $S$. fredii interactions with both American and Asiatic soybeans (Jiao et al. 2016). Our results suggest that MucR1 could either affect different steps of symbiosis in different hosts, affect the same step, such as nodule formation, or both in a different way in different plant species. In addition, the transcriptome analysis carried out in different rhizobia indicates that the same protein (MucR and RosR) can regulate similar sets of genes but in opposite ways in different species, as is the case for motility genes (repressed in Sinorhizobium spp., induced in R. leguminosarum bv. trifolii). Clearly, further research is required to elucidate the different processes controlled by MucR/RosR in rhizobia and how these regulators are integrated into the highly complex rhizobial symbiotic signaling.

\section{MATERIALS AND METHODS}

Basic molecular and microbiological techniques.

Sinorhizobium fredii strains were grown at $28^{\circ} \mathrm{C}$ on tryptone yeast (TY) medium (Beringer 1974), YM medium (Vincent 1970), MGM medium (O'Toole and Kolter 1998), or Bromfield medium (Sourjik and Schmitt 1996). Escherichia coli was cultured on Luria-Bertani (LB) medium (Sambrook and Russell $2001)$ at $37^{\circ} \mathrm{C}$. When required, the media were supplemented with the appropriate antibiotics as described by Vinardell et al. (2004a). Genistein was dissolved in ethanol at a concentration of $1 \mathrm{mg} / \mathrm{ml}$ and was used at $1 \mu \mathrm{g} / \mathrm{ml}$. Plasmids were transferred from $E$. coli to rhizobia by triparental mating, using plasmid pRK2013 as a helper, as described by Simon (1984). $\beta$-galactosidase assays were performed as described by Vinardell et al. (2004a).

Recombinant DNA techniques were performed according to the general protocols of Sambrook and Russell (2001). For hybridization, DNA was blotted to Amersham Hybond-N nylon membranes and the DigDNA method of Roche was employed according to manufacturer's instructions. PCR amplifications were performed as previously described (Vinardell et al. 2004b). All primer pairs used in this work are listed in Supplementary Table S1.

\section{Motility assays.}

Swimming was examined on plates prepared with Bromfield medium containing $0.3 \%$ Bacto agar and inoculated with $3-\mu \mathrm{l}$ aliquots of rhizobial cultures grown in TY $\left(\mathrm{OD}_{600}=1\right)$. Surface motility was analyzed on semisolid minimal medium plates with glycerol as carbon source, containing $0.4 \%$ agarose and $22 \mu \mathrm{M}$ ferric chloride after sterilization. Plates were supplemented with genistein for surface motility and were inoculated with $2 \mu \mathrm{l}$ of washed 10 -fold concentrated cultures grown in TY broth to the late exponential phase. The migration zone was determined as the colony diameter $(\mathrm{mm})$ after 24,48 , and $72 \mathrm{~h}$ (for swimming and surface motility on semisolid minimal medium) of incubation. 


\section{Autoaggregation, biofilm assays, and EPS production.}

Bacterial autoaggregation assays were performed as previously described by Sorroche et al. (2012), with some modifications. The bacteria were grown in $4 \mathrm{ml}$ of MGM medium supplemented with appropriate antibiotics, were incubated for $24 \mathrm{~h}$ at $28^{\circ} \mathrm{C}$, were diluted 1:100 in MGM, and were incubated for $96 \mathrm{~h}$ under the same conditions. The bacterial suspensions $(5 \mathrm{ml})$ were then transferred into a glass tube and were allowed to settle for $24 \mathrm{~h}$ at $4^{\circ} \mathrm{C}$. A $0.2-\mathrm{ml}$ aliquot of the upper portion of the suspension was transferred onto a microtiter plate, and the final $\mathrm{OD}_{600}\left(\mathrm{OD}_{\text {final }}\right)$ was measured. A control tube was vortexed for $30 \mathrm{~s}$, and the initial $\mathrm{OD}_{600}\left(\mathrm{OD}_{\text {initial }}\right)$ was determined. The autoaggregation percentage was calculated as follows: $100-$ $\left[1-\left(\mathrm{OD}_{\text {final }} / \mathrm{OD}_{\text {initial }}\right)\right]$. The values of each treatment were compared with those of $S$. fredii HH103, using the Mann-Whitney nonparametrical test.

Assays for biofilm formation on plastic surfaces were carried out as described by Margaret et al. (2013). Data presented are the mean of at least three independent experiments performed in duplicate; in each experiment, at least 12 wells for each treatment were measured. In order to visualize biofilm formation on glass surfaces, $S$. fredii strains harboring plasmid pSKDSRED (Kelly et al. 2013) were cultured in MGM medium $\left(28^{\circ} \mathrm{C}\right.$, static conditions) in sterile glass Coplin staining jars containing glass slides, as described by Rodríguez-Navarro et al. (2014). At 1 and 4 days after inoculation, glass slides were collected and air dried, were rinsed with $\mathrm{NaCl} 0.9 \%$, were air dried, and were observed and photographed, using Nikon Eclipse Ti-U epifluorescence microscopy with an excitation and emission wavelength of 554 and $586 \mathrm{~nm}$, respectively. Three different sections of the glass slide were examined (from the bottom to the upper part of the slide): 5, 28, and $49 \mathrm{~mm}$, the latter corresponding to the liquid-air interface.

For analysis of EPS production in solid media, 20- $\mu$ d droplets of YMB-grown early log $\left(\mathrm{OD}_{600}=0.4\right)$ cultures were placed onto YMA plates (supplemented or not with genistein), were incubated at $28^{\circ} \mathrm{C}$ for $96 \mathrm{~h}$, and were photographed. For EPS quantification, bacterial cultures were grown on $\mathrm{YM}$ for $96 \mathrm{~h}$ at $28^{\circ} \mathrm{C}\left(\mathrm{OD}_{600}=1.2\right.$ to 1.3$)$ under shaking conditions. Cells were removed by centrifugation $(20,000 \times g, 15 \mathrm{~min})$ and total carbohydrate amounts of the EPS-containing supernatants were determined, using the anthrone- $\mathrm{H}_{2} \mathrm{SO}_{4}$ method, which measures the total reducing sugar content in a given sample, as previously described (Abarca-Grau et al. 2012). Four independent experiments, in duplicate, were carried out. The amounts of EPS produced by each strain were compared with that of the parental strain by the Mann-Whitney nonparametric test.

\section{Isolation of EPS and extracellular CG and analysis by NMR.}

Culture supernatant (1 liter) was concentrated to $20 \%$ of its original volume on a rotary evaporator and was then mixed with ethanol (3 vol). The resulting precipitate contained the EPS, which was removed, by centrifugation, resuspended, and purified by dialysis. Supernatant was concentrated to $5 \%$ of their original volume, and $10 \mathrm{ml}$ of it was mixed with ethanol (10 vol) to precipitate the low-molecular weight fraction that contained CG (Gil Serrano et al. 1993). The resulting precipitate was redissolved in water and was dialyzed with a $10-\mathrm{kDa}$ JumboSep device (Pall Corporation). The diffusate was concentrated on a rotary evaporator and salts were removed by size-exclusion chromatography on BioGel P-2 (85 by $2 \mathrm{~cm}$ ) with water as eluent. Fractions containing carbohydrates were detected using a refractive-index detector and the orcinol-sulfuric acid method on thin-layer chromatography plates and were then analyzed by NMR. Samples ( 1 to $5 \mathrm{mg}$ ) were deuterium-exchanged several times by freeze-drying from $\mathrm{D}_{2} \mathrm{O}$ and were then examined in solution ( 1 to $5 \mathrm{mg}$ to $750 \mathrm{ml}$ of $99.90 \% \mathrm{D}_{2} \mathrm{O}$ ). Spectra were recorded on a Bruker AV500 spectrometer operating at 500.13 $\mathrm{MHz}\left({ }^{1} \mathrm{H}\right)$. Chemical shifts are given in ppm, using the HDO signal $(4.22 \mathrm{ppm}$ at $353 \mathrm{~K}$ and 4.71 at $303 \mathrm{~K}$ ) as a reference (Gottlieb et al. 1997).

\section{Analysis of LPS and KPS.}

LPS extraction from bacterial cultures grown on solid TY medium, separation on sodium dodecyl sulfate (SDS)-PAGE gels and silver staining or inmuno-staining with the monoclonal antibody NB6-228.22 were as described by Buendía-Clavería et al. (2003). KPS were extracted from bacterial cultures grown on solid TY medium and were analyzed by PAGE as described by Hidalgo et al. (2010). The detection of $S$. fredii KPS and CG by ${ }^{1} \mathrm{H}-\mathrm{NMR}$ was performed as previously described (CrespoRivas et al. 2009; Hidalgo et al. 2010).

\section{Nodulation assays.}

Nodulation assays on Glycine max (L.) Merr. cv. Williams and Lotus burttii were carried out, as previously described by Crespo-Rivas et al. (2007) and Sandal et al. (2012), in a plantgrowth chamber, with a $16-\mathrm{h}$ photoperiod at $25^{\circ} \mathrm{C}$ in the light and $18^{\circ} \mathrm{C}$ in the dark. For soybean, each plant was inoculated with approximately $10^{8}$ bacteria and, then, was grown for at least 6 weeks. Plant tops were dried at $70^{\circ} \mathrm{C}$ for $48 \mathrm{~h}$ and were weighed. In the case of Lotus plants, four germinated seeds were transferred to each Leonard jar assembly and were inoculated with $10^{8}$ bacteria. Inoculated Lotus plants were grown for 6 to 9 weeks. Bacterial isolation from surface-sterilized nodules was carried out as previously described by Buendía-Clavería et al. (2003). Nitrogenase activity of nodules was assessed by ARA (acetylene reduction assay), as described by Buendía-Clavería and associates (1989). For the different parameters analyzed, the values of each treatment were compared with those of $S$. fredii HH103, using the Mann-Whitney nonparametrical test.

\section{eGFP fluorescence assays.}

For measuring transcription of $S$. fredii $\mathrm{HH} 103$ mucRl, its promoter region plus the first codon was PCR-amplified and digested with $\mathrm{XbaI}$ and HindIII and was fused, in frame, to the gene coding for eGFP, contained in plasmid pPHU231 (McIntosh et al. 2008), resulting in plasmid pMUS1196. For eGFP fluorescence assays, the method described by McIntosh et al. (2008) was used, with modifications. Transconjugants of $S$. fredii HH103 Rif $^{\mathrm{R}}$ and its $\triangle m u c R l$ derivative containing plasmid pMUS1196 were first cultivated in YM broth at $28^{\circ} \mathrm{C}$, with agitation, until medium exponential phase $\left(\mathrm{OD}_{600}=0.5\right.$ to 0.6$)$, were diluted to $\mathrm{OD}_{600}=0.04$, and $100-\mu$ l aliquots were inoculated into microtiter plate wells. The cell density $\left(\mathrm{OD}_{600}\right)$ and eGFP fluorescence (excitation at $485 \mathrm{~nm}$ and emission at $528 \mathrm{~nm}$ with a $35 \%$ scanning rate) were measured using a Tecan Infinite M200 reader (Tecan Trading AG). Data presented (eGFP fluorescence/ $\mathrm{OD}_{600}$ ) are the medians of two independent experiments performed in duplicate; in each duplicate, at least six wells for each treatment were measured. The eGFP fluorescence emitted for the corresponding strains carrying the empty vector pPHU231 was subtracted in all cases. The values obtained for HH103 pMUS1196 and HH103 $\Delta m u c R 1$ pMUS1196 were compared, using the Mann-Whitney nonparametrical test.

\section{EMSA assays.}

Expression and purification of the fusion proteins. The HH103 mucRl gene was PCR-amplified, using the attB1mucR1 and attB2mucR1 primers, which contain the sequences necessary for Gateway cloning. The amplified DNA fragment was subcloned into plasmid pDONR221, generating the pMUS1203 plasmid. Then, the mucRl gene was subcloned into the pGEX-KG 
Gateway destination vector, to give pGEX-KGmucRl. Vector pGEX-KG added an in frame GST tag to the N-terminus of mucR1. Plasmid pGEX-KGmucRl was transferred to E. coli BL21, following the methodology described by Chung et al. (1989). Expression of the fusion protein was performed, following the general protocols described by Sambrook and Russell (2001). Briefly, E. coli BL21 carrying plasmid pGEX-KGmucR1 was inoculated in $5 \mathrm{ml}$ of $\mathrm{LB}$ and was grown overnight at $37^{\circ} \mathrm{C}$. Cultures were transferred to $100 \mathrm{ml}$ of $\mathrm{LB}$ supplemented with ampicillin and were incubated with shaking at $37^{\circ} \mathrm{C}$ until late exponential phase $\left(\mathrm{OD}_{600}=0.8\right)$ and, then, were induced with $1 \mathrm{mM}$ isopropyl $\beta$-D-1-thiogalactopyranoside for at least $4 \mathrm{~h}$ and were centrifuged at approximately $2,000 \times g$ for $20 \mathrm{~min}$ at $4^{\circ} \mathrm{C}$. The supernatants were discarded and the pellets were stored at $-80^{\circ} \mathrm{C}$ until use. Proteins were extracted and purified using a glutathione sepharose 4B resin, following the protocol described by Smith and Johnson (1988), and the purified proteins were quantified using a Nanodrop apparatus (Thermo Fisher Scientific).

Proteins were separated by SDS-PAGE, using the discontinuous buffer system of Laemmli (1970). Electrophoresis was performed on SDS $12 \%(\mathrm{~m} / \mathrm{v})$ polyacrylamide gels, and proteins were visualized using PageBlue (Thermo Fisher Scientific), following the manufacturer's instructions. For immunostaining, proteins were separated and electroblotted to Immun-Blot polyvinylidene diflouride membranes (Bio-Rad), using a Mini Trans-Blot electrophoretic transfer cell (Bio-Rad). Membranes were blocked with Tris-buffered saline containing $2 \%(\mathrm{~m} / \mathrm{v})$ bovine serum albumin (BSA) and were incubated with antibodies raised against GST (Cell Signaling) diluted 1:1,000 in the same solution. Antirabbit immunoglobulin antibodies (AP-conjugate) were used as secondary antibodies. Reaction results were visualized using nitroblue tetrazolium-5-bromo4-chloro-3-indolyl phosphate.

EMSA analysis. Cy5-labeled DNA fragments 1 to 5 were amplified by PCR, using different primers in such a way that all the fragments were labeled with Cy5. Each labeled DNA fragment in a concentration of $50 \mathrm{ng}$ was mixed with purified MucR1-GST at different concentrations $(0,0.5$, and $5 \mu \mathrm{g})$ in a reaction buffer containing $50 \mathrm{mM}$ Tris- $\mathrm{HCl}$ [pH 8.0], $100 \mathrm{mM} \mathrm{NaCl}, 0.1 \mathrm{mM}$ $\mathrm{Mg}_{2} \mathrm{SO}_{4}, 4.5 \%$ glycerol, and BSA at $0.5 \mathrm{mg} / \mathrm{ml}$, to give a final volume of $25 \mu \mathrm{l}$. After $30 \mathrm{~min}$ of incubation at $20^{\circ} \mathrm{C}$, the mixture was loaded into a $1.5 \%$ nondenaturing agarose gel prepared in

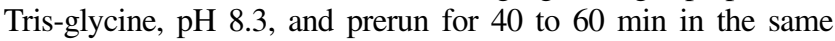
buffer at $4^{\circ} \mathrm{C}$. The electrophoresis was carried out at $90 \mathrm{~V}$ for $2 \mathrm{~h}$ at $4^{\circ} \mathrm{C}$ in Tris-glycine, $\mathrm{pH}$ 8.3. Gel images were acquired, using a Typhoon 3000 variable mode imager (Amersham Bioscience).

\section{qRT-PCR.}

Results obtained in the RNA-Seq analysis were validated by qRT-PCR of 20 selected genes, which represented DEG and nonDEG in the two strains in the absence and presence of genistein. Total RNA was isolated using the High Pure RNA isolation kit (Roche) and RNase free DNA set (Qiagen), according to the manufacturer's instructions. This (DNA free) RNA was reverse transcribed to cDNA by using PrimeScript RT reagent kit with gDNA Eraser (Takara). qPCR was performed using a LightCycler 480 (Roche, Switzerland) with the following conditions: $95^{\circ} \mathrm{C}$, $10 \mathrm{~min} ; 95^{\circ} \mathrm{C}, 30 \mathrm{~s} ; 50^{\circ} \mathrm{C}, 30 \mathrm{~s} ; 72^{\circ} \mathrm{C}, 20 \mathrm{~s} ; 40$ cycles, followed by the melting curve profile from 60 to $95^{\circ} \mathrm{C}$, to verify the specificity of the reaction. The $S$. fredii $\mathrm{HH} 103$ 16S rRNA was used as an internal control to normalize gene expression. The fold changes of two biological samples with three technical replicates in each condition were obtained using the $\Delta \Delta \mathrm{C}_{\mathrm{t}}$ method (Pfaffl et al. 2002).

\section{RNA-Seq.}

The RNA-Seq data discussed in this publication have been deposited in the Sequence Read Archive of the National Center for Biotechnology Information (BioProject database) under the BioProjects ID PRJNA313151 and PRJNA324263. All samples showed more than $90 \%$ of proper pair reads. Three different RNA-Seq metrics for quality control, GC content, duplicate distribution, and the distribution of respective genetic coordinates were performed. A normalization of the quantification data was also carried out before all subsequent analysis to avoid statistical deviations due to differences in library and genetic sizes (Hansen et al. 2012).

\section{ACKNOWLEDGMENTS}

We thank the Biology, Microscopy, NMR, and Mass Spectrometry Services of the Centro de Investigación, Tecnología e Innovación (CITIUS) of the University of Seville. We also acknowledge J.-C. Treviño (Sistemas Genómicos S.L., Spain) for his valuable help during all the bioinformatics analyses, and J. Trow (Sequence Read Archive from the National Center for Biotechnology Information) for his technical assistance during the RNA-Seq data submission. We also thank D.-N. Rodríguez-Navarro for providing Lotus burttii seeds. This work was supported by grants from the Spanish Ministry of Science and Innovation (BIO2011-30229 and AGL2012-38831) and the Andalusia Government (P07-CVI-07500). S. A. Jurado and P. Navarro-Gomez are recipients of Ph.D. grants from the V Plan Propio de Investigación of the University of Seville.

\section{LITERATURE CITED}

Abarca-Grau, A. M., Burbank, L. P., de Paz, H. D., Crespo-Rivas, J. C., MarcoNoales, E., López, M. M., Vinardell, J. M., von Bodman, S. B., and Penyalver, R. 2012. Role for Rhizobium rhizogenes K84 cell envelope polysaccharides in surface interactions. Appl. Environ. Microbiol. 78:1644-1651.

Acosta-Jurado, S., Navarro-Gómez, P., Murdoch, P. S., Crespo-Rivas, J. C., Jie, S., Cuesta-Berrio, L., Ruiz-Sainz, J. E., Rodríguez-Carvajal, M. A., and Vinardell, J. M. 2016. Exopolysaccharide production by Sinorhizobium fredii HH103 is repressed by genistein in a NodD1-dependent manner. PLoS One 11:e0160499.

Bahlawane, C., McIntosh, M., Krol, E., and Becker, A. 2008. Sinorhizobium meliloti regulator MucR couples exopolysaccharide synthesis and motility. Mol. Plant-Microbe Interact. 21:1498-1509.

Beringer, J. E. 1974. R factor transfer in Rhizobium leguminosarum. J. Gen. Microbiol. 84:188-198.

Bertram-Drogatz, P. A., Quester, I., Becker, A., and Pühler, A. 1998. The Sinorhizobium meliloti MucR protein, which is essential for the production of high-molecular-weight succinoglycan exopolysaccharide, binds to short DNA regions upstream of exoH and exoY. Mol. Gen. Genet. 257:433-441.

Bertram-Drogatz, P. A., Rüberg, S., Becker, A., and Pühler, A. 1997. The regulatory protein MucR binds to a short DNA region located upstream of the mucR coding region in Rhizobium meliloti. Mol. Gen. Genet. 254:529-538.

Buendía-Clavería, A. M., Chamber, M., and Ruiz-Sainz, J. E. 1989. A comparative study of the physiological characteristics, plasmid content and symbiotic properties of different Rhizobium fredii strains. Syst. Appl. Microbiol. 12:203-209.

Buendía-Clavería, A. M., Moussaid, A., Ollero, F. J., Vinardell, J. M., Torres, A., Moreno, J., Gil Serrano, A. M., Rodríguez-Carvajal, M. A., Tejero-Mateo, P., Peart, J. L., Brewin, N. J., and Ruiz-Sainz, J. E. 2003. A purL mutant of Sinorhizobium fredii $\mathrm{HH} 103$ is symbiotically defective and altered in its lipopolysaccharide. Microbiology 149:1807-1818.

Caswell, C. C., Elhassanny, A. E., Planchin, E. E., Roux, C. M., WeeksGorospe, J. N., Ficht, T. A., Dunman, P. M., and Roop, R. M., 2nd. 2013. Diverse genetic regulon of the virulence-associated transcriptional regulator MucR in Brucella abortus 2308. Infect. Immun. 81:1040-1051.

Chen, H., Gao, K., Kondorosi, E., Kondorosi, A., and Rolfe, B. G. 2005. Functional genomic analysis of global regulator NolR in Sinorhizobium meliloti. Mol. Plant-Microbe Interact. 18:1340-1352.

Chou, A. Y., Archdeacon, J., and Kado, C. I. 1998. Agrobacterium transcriptional regulator Ros is a prokaryotic zinc finger protein that regulates the plant oncogene ipt. Proc. Natl. Acad. Sci. U.S.A. 95:52935298.

Chung, C. T., Niemela, S. L., and Miller, R. H. 1989. One-step preparation of competent Escherichia coli: Transformation and storage of bacterial cells in the same solution. Proc. Natl. Acad. Sci. U.S.A. 86:2172-2175.

Crespo-Rivas, J. C., Margaret, I., Hidalgo, A., Buendía-Clavería, A. M., Ollero, F. J., López-Baena, F. J., del Socorro Murdoch, P., RodríguezCarvajal, M. A., Soria-Díaz, M. E., Reguera, M., Lloret, J., Sumpton, D. P., Mosely, J. A., Thomas-Oates, J. E., van Brussel, A. A. N., Gil 
Serrano, A., Vinardell, J. M., and Ruiz-Sainz, J. E. 2009. Sinorhizobium fredii $\mathrm{HH} 103$ cgs mutants are unable to nodulate determinate- and indeterminate nodule-forming legumes and overproduce an altered EPS. Mol. Plant-Microbe Interact. 22:575-588.

Crespo-Rivas, J. C., Margaret, I., Pérez-Montaño, F., López-Baena, F. J., Vinardell, J. M., Ollero, F. J., Moreno, J., Ruiz-Sainz, J. E., and BuendíaClavería, A. M. 2007. A pyrF auxotrophic mutant of Sinorhizobium fredii $\mathrm{HH} 103$ impaired in its symbiotic interactions with soybean and other legumes. Int. Microbiol. 10:169-176.

de Maagd, R. A., Wijffelman, C. A., Pees, E., and Lugtenberg, B. J. 1988. Detection and subcellular localization of two Sym plasmid-dependent proteins of Rhizobium leguminosarum biovar viciae. J. Bacteriol. 170: 4424-4427.

Dong, H., Liu, W., Peng, X., Jing, Z., and Wu, Q. 2013. The effects of MucR on expression of type IV secretion system, quorum sensing system and stress responses in Brucella melitensis. Vet. Microbiol. 166:535-542.

Downie, J. A. 2010. The roles of extracellular proteins, polysaccharides and signals in the interactions of rhizobia with legume roots. FEMS Microbiol. Rev. 34:150-170.

Fumeaux, C., Radhakrishnan, S. K., Ardissone, S., Théraulaz, L., Frandi, A., Martins, D., Nesper, J., Abel, S., Jenal, U., and Viollier, P. H. 2014. Cell cycle transition from S-phase to G1 in Caulobacter is mediated by ancestral virulence regulators. Nat. Commun. 5:4081.

Geiger, O., Weissborn, A. C., and Kennedy, E. P. 1991. Biosynthesis and excretion of cyclic glucans by Rhizobium meliloti 1021. J. Bacteriol. 173:3021-3024

Gil Serrano, A. M., Franco-Rodriguez, G., Gonzalez-Jiménez, I., Tejero Mateo, P., Molina, J. M., Dobado, J. A., Megias, M., and Romero, M. J. 1993. The structure and molecular mechanics calculations of the cyclic (1-2)- $\beta$-D-glucan secreted by Rhizobium tropici CIAT 899. J. Mol. Struct. 301:211-226.

Gottlieb, H. E., Kotlyar, V., and Nudelman, A. 1997. NMR chemical shifts of common laboratory solvents as trace impurities. J. Org. Chem. 62: $7512-7515$.

Griffitts, J. S., Carlyon, R. E., Erickson, J. H., Moulton, J. L., Barnett, M. J., Toman, C. J., and Long, S. R. 2008. A Sinorhizobium meliloti osmosensory two-component system required for cyclic glucan export and symbiosis. Mol. Microbiol. 69:479-490.

Hansen, K. D., Irizarry, R. A., and Wu, Z. 2012. Removing technical variability in RNA-seq data using conditional quantile normalization. Biostatistics 13:204-216.

Hidalgo, A., Margaret, I., Crespo-Rivas, J. C., Parada, M., Murdoch, Pdel. S., López, A., Buendía-Clavería, A. M., Moreno, J., Albareda, M. Gil Serrano, A. M., Rodríguez-Carvajal, M. A., Palacios, J. M., RuizSainz, J. E., and Vinardell, J. M. 2010. The rkpU gene of Sinorhizobium fredii $\mathrm{HH} 103$ is required for bacterial $\mathrm{K}$-antigen polysaccharide production and for efficient nodulation with soybean but not with cowpea. Microbiology 156:3398-3411.

Huyghe, A., Bakkou, N., and Perret, X. 2015. Profiling symbiotic responses of Sinorhizobium fredii strain NGR234 with RNA-seq. Pages 1153-1162 in: Biological Nitrogen Fixation. F. J. de Bruijn, ed. Vol. 2. John Wiley \& Sons, New York.

Janczarek, M. 2011. Environmental signals and regulatory pathways that influence exopolysaccharide production in rhizobia. Int. J. Mol. Sci. 12: 7898-7933.

Janczarek, M., Jaroszuk-Sciseł, J., and Skorupska, A. 2009. Multiple copies of $r o s R$ and pssA genes enhance exopolysaccharide production, symbiotic competitiveness and clover nodulation in Rhizobium leguminosarum bv. trifolii. Antonie van Leeuwenhoek 96:471-486.

Janczarek, M., Kutkowska, J., Piersiak, T., and Skorupska, A. 2010 Rhizobium leguminosarum bv. trifolii rosR is required for interaction with clover, biofilm formation and adaptation to the environment. BMC Microbiol. 10:284.

Janczarek, M., Rachwał, K., Marzec, A., Grządziel, J., and PalusińskaSzysz, M. 2015. Signal molecules and cell-surface components involved in early stages of the legume-rhizobium interactions. Appl. Soil Ecol 85:94-113.

Janczarek, M., and Skorupska, A. 2007. The Rhizobium leguminosarum by. trifolii RosR: Transcriptional regulator involved in exopolysaccharide production. Mol. Plant-Microbe Interact. 20:867-881.

Janczarek, M., and Skorupska, A. 2011. Modulation of rosR expression and exopolysaccharide production in Rhizobium leguminosarum bv. trifolii by phosphate and clover root exudates. Int. J. Mol. Sci. 12:4132-4155.

Jiao, J., Wu, L. J., Zhang, B., Hu, Y., Li, Y., Zhang, X. X., Guo, H. J., Liu, L. X., Chen, W. X., Zhang, Z., and Tian, C. F. 2016. MucR is required for transcriptional activation of conserved ion transporters to support nitrogen fixation of Sinorhizobium fredii in soybean nodules. Mol. PlantMicrobe Interact. 29:352-361
Keller, M., Roxlau, A., Weng, W. M., Schmidt, M., Quandt, J., Niehaus, K., Jording, D., Arnold, W., and Pühler, A. 1995. Molecular analysis of the Rhizobium meliloti mucR gene regulating the biosynthesis of the exopolysaccharides succinoglycan and galactoglucan. Mol. Plant-Microbe Interact. 8:267-277.

Kelly, S. J., Muszyński, A., Kawaharada, Y., Hubber, A. M., Sullivan, J. T. Sandal, N., Carlson, R. W., Stougaard, J., and Ronson, C. W. 2013 Conditional requirement for exopolysaccharide in the MesorhizobiumLotus symbiosis. Mol. Plant-Microbe Interact. 26:319-329.

Laemmli, U. K. 1970. Cleavage of structural proteins during the assembly of the head of bacteriophage T4. Nature 227:680-685.

Lang, K., Lindemann, A., Hauser, F., and Göttfert, M. 2008. The genistein stimulon of Bradyrhizobium japonicum. Mol. Genet. Genomics 279:203-211

López-Baena, F. J., Monreal, J. A., Pérez-Montaño, F., Guasch-Vidal, B., Bellogín, R. A., Vinardell, J. M., and Ollero, F. J. 2009. The absence of Nops secretion in Sinorhizobium fredii HH103 increases GmPR1 expression in Williams soybean. Mol. Plant-Microbe Interact. 22: 1445-1454.

López-Baena, F. J., Ruiz-Sainz, J. E., Rodríguez-Carvajal, M. A., and Vinardell, J. M. 2016. Bacterial molecular signals in the Sinorhizobium fredii-soybean symbiosis. Int. J. Mol. Sci. 17:755

Margaret, I., Becker, A., Blom, J., Bonilla, I., Goesmann, A., Göttfert, M., Lloret, J., Mittard-Runte, V., Rückert, C., Ruiz-Sainz, J. E., Vinardell, J. M., and Weidner, S. 2011. Symbiotic properties and first analyses of the genomic sequence of the fast growing model strain Sinorhizobium fredii HH103 nodulating soybean. J. Biotechnol. 155:11-19.

Margaret, I., Crespo-Rivas, J. C., Acosta-Jurado, S., Buendía-Clavería, A. M., Cubo, M. T., Gil-Serrano, A., Moreno, J., Murdoch, P. S., Rodríguez-Carvajal, M. A., Rodríguez-Navarro, D. N., Ruiz-Sainz, J. E., Sanjuán, J., Soto, M. J., and Vinardell, J. M. 2012. Sinorhizobium fredii $\mathrm{HH} 103$ rkp-3 genes are required for K-antigen polysaccharide structure and are essential for infection of legumes forming determinate nodules. Mol. Plant-Microbe Interact. 25:825-838.

Margaret, I., Lucas, M. M., Acosta-Jurado, S., Buendía-Clavería, A. M., Fedorova, E., Hidalgo, Á., Rodríguez-Carvajal, M. A., RodríguezNavarro, D. N., Ruiz-Sainz, J. E., and Vinardell, J. M. 2013. The Sinorhizobium fredii $\mathrm{HH} 103$ lipopolysaccharide is not only relevant at early soybean nodulation stages but also for symbiosome stability in mature nodules. PLoS One 8:e74717.

McIntosh, M., Krol, E., and Becker, A. 2008. Competitive and cooperative effects in quorum-sensing-regulated galactoglucan biosynthesis in Sinorhizobium meliloti. J. Bacteriol. 190:5308-5317.

Mesa, S., Hauser, F., Friberg, M., Malaguti, E., Fischer, H. M., and Hennecke, H. 2008. Comprehensive assessment of the regulons controlled by the FixLJ-FixK ${ }_{2}-$ FixK $_{1}$ cascade in Bradyrhizobium japonicum. J. Bacteriol. 190:6568-6579.

Mirabella, A., Terwagne, M., Zygmunt, M. S., Cloeckaert, A., De Bolle, X. and Letesson, J. J. 2013. Brucella melitensis MucR, an orthologue of Sinorhizobium meliloti MucR, is involved in resistance to oxidative, detergent, and saline stresses and cell envelope modifications. J. Bacteriol. 195:453-465.

Mueller, K., and González, J. E. 2011. Complex regulation of symbiotic functions is coordinated by MucR and quorum sensing in Sinorhizobium meliloti. J. Bacteriol. 193:485-496.

O’Toole, G. A., and Kolter, R. 1998. Initiation of biofilm formation in Pseudomonas fluorescens WCS365 proceeds via multiple, convergent signalling pathways: A genetic analysis. Mol. Microbiol. 28:449-461.

Oldroyd, G. E. 2013. Speak, friend, and enter: Signalling systems that promote beneficial symbiotic associations in plants. Nat. Rev. Microbiol 11:252-263.

Peix, A., Ramírez-Bahena, M. H., Velázquez, E., and Bedmar, E. J. 2015. Bacterial associations with legumes. Crit. Rev. Plant Sci. 34:17-42.

Pérez-Montaño, F., Jiménez-Guerrero, I., Acosta-Jurado, S., NavarroGómez, P., Ollero, F. J., Ruiz-Sainz, J. E., López-Baena, F. J., and Vinardell, J. M. 2016. A transcriptomic analysis of the effect of flavonoids on Sinorhizobium fredii HH103 reveals novel rhizobial genes putatively involved in symbiosis. Scientific Reports 6:31592.

Pfaffl, M. W., Horgan, G. W., and Dempfle, L. 2002. Relative expression software tool (REST) for group-wise comparison and statistical analysis of relative expression results in real-time PCR. Nucleic Acids Res. 30: e36.

Rachwał, K., Matczyńska, E., and Janczarek, M. 2015. Transcriptome profiling of a Rhizobium leguminosarum bv. trifolii ros $R$ mutant reveals the role of the transcriptional regulator RosR in motility, synthesis of cell-surface components, and other cellular processes. BMC Genomics 16:1111.

Rice, P., Longden, I., and Bleasby, A. 2000. EMBOSS: The European molecular biology open software suite. Trends Genet. 16:276-277. 
Rodríguez-Navarro, D. N., Rodríguez-Carvajal, M. A., Acosta-Jurado, S., Soto, M. J., Margaret, I., Crespo-Rivas, J. C., Sanjuán, J., Temprano, F., Gil Serrano, A., Ruiz-Sainz, J. E., and Vinardell, J. M. 2014. Structure and biological roles of Sinorhizobium fredii HH103 exopolysaccharide. PLoS One 9:e115391.

Sambrook, J., and Russell, D. 2001. Molecular Cloning: A Laboratory Manual, 3rd Ed. Cold Spring Harbor Laboratory, Cold Spring Harbor, NY, U.S.A

Sandal, N., Jin, H., Rodriguez-Navarro, D. N., Temprano, F., Cvitanich, C., Brachmann, A., Sato, S., Kawaguchi, M., Tabata, S., Parniske, M., RuizSainz, J. E., Andersen, S. U., and Stougaard, J. 2012. A set of Lotus japonicus Gifu $\times$ Lotus burttii recombinant inbred lines facilitates mapbased cloning and QTL mapping. DNA Res. 19:317-323.

Simon, R. 1984. High frequency mobilization of gram-negative bacterial replicons by the in vitro constructed Tn5-Mob transposon. Mol. Gen. Genet. 196:413-420.

Smith, D. B., and Johnson, K. S. 1988. Single-step purification of polypeptides expressed in Escherichia coli as fusions with glutathione $S$-transferase. Gene 67:31-40.

Sorroche, F. G., Spesia, M. B., Zorreguieta, A., and Giordano, W. 2012. A positive correlation between bacterial autoaggregation and biofilm formation in native Sinorhizobium meliloti isolates from Argentina. Appl. Environ. Microbiol. 78:4092-4101.

Sourjik, V., and Schmitt, R. 1996. Different roles of CheY1 and CheY2 in the chemotaxis of Rhizobium meliloti. Mol. Microbiol. 22:427-436.

Suzaki, T., and Kawaguchi, M. 2014. Root nodulation: A developmental program involving cell fate conversion triggered by symbiotic bacterial infection. Curr. Opin. Plant Biol. 21:16-22.

Vinardell, J. M., Acosta-Jurado, S., Zehner, S., Göttfert, M., Becker, A., Baena, I., Blom, J., Crespo-Rivas, J. C., Goesmann, A., Jaenicke, S.,
Krol, E., McIntosh, M., Margaret, I., Pérez-Montaño, F., SchneikerBekel, S., Serranía, J., Szczepanowski, R., Buendía, A. M., Lloret, J., Bonilla, I., Pühler, A., Ruiz-Sainz, J. E., and Weidner, S. 2015. The Sinorhizobium fredii HH103 genome: A comparative analysis with $S$. fredii strains differing in their symbiotic behavior with soybean. Mol. Plant-Microbe Interact. 28:811-824.

Vinardell, J. M., López-Baena, F. J., Hidalgo, A., Ollero, F. J., Bellogín, R., del Rosario Espuny, M., Temprano, F., Romero, F., Krishnan, H. B., Pueppke, S. G., and Ruiz-Sainz, J. E. 2004a. The effect of FITA mutations on the symbiotic properties of Sinorhizobium fredii varies in a chromosomal-background-dependent manner. Arch. Microbiol. 181: 144-154.

Vinardell, J. M., Ollero, F. J., Hidalgo, A., López-Baena, F. J., Medina, C., Ivanov-Vangelov, K., Parada, M., Madinabeitia, N., Espuny, Mdel. R., Bellogín, R. A., Camacho, M., Rodríguez-Navarro, D. N., Soria-Díaz, M. E., Gil Serrano, A. M., and Ruiz-Sainz, J. E. 2004b. NolR regulates diverse symbiotic signals of Sinorhizobium fredii HH103. Mol. PlantMicrobe Interact. 17:676-685.

Vincent, J. M. 1970. The modified Fåhraeus slide technique. Appendix III. Pages 144-145 in: A Manual for the Practical Study of Root Nodule Bacteria. J. M. Vincent, ed. Blackwell Scientific, Oxford.

Wang, Y., Hay, I. D., Rehman, Z. U., and Rehm, B. H. 2015. Membraneanchored MucR mediates nitrate-dependent regulation of alginate production in Pseudomonas aeruginosa. Appl. Microbiol. Biotechnol. 99:7253-7265.

Weidner, S., Becker, A., Bonilla, I., Jaenicke, S., Lloret, J., Margaret, I., Pühler, A., Ruiz-Sainz, J. E., Schneiker-Bekel, S., Szczepanowski, R., Vinardell, J. M., Zehner, S., and Göttfert, M. 2012. Genome sequence of the soybean symbiont Sinorhizobium fredii HH103. J. Bacteriol. 194: 1617-1618. 